\title{
Cessation of deep convection in the open Southern Ocean under anthropogenic climate
}

change

Casimir de Lavergne ${ }^{1 *}$, Jaime B. Palter ${ }^{1}$, Eric D. Galbraith ${ }^{2}$, Raffaele Bernardello ${ }^{3}$, Irina $\operatorname{Marinov}^{3}$

${ }^{1}$ Department of Atmospheric and Oceanic Sciences, Burnside Hall, McGill University, 805 Sherbrooke Street West, Montreal, Quebec H3A 0B9, Canada.

2 Department of Earth and Planetary Sciences, McGill University, 3450 University Street, Montreal, Quebec H3A 0E8, Canada.

${ }^{3}$ Department of Earth and Environmental Science, Hayden Hall, University of Pennsylvania, 240 S. 33rd Street, Philadelphia, PA 19104-6316, USA.

*e-mail: casimir.delavergne@gmail.com 
In 1974, newly available satellite observations unveiled the presence of a giant ice-free area, or polynya, within the Antarctic ice pack of the Weddell Sea, which persisted during the two following winters ${ }^{1}$. Subsequent research showed that deep convective overturning had opened a conduit between the surface and the abyssal ocean, and had maintained the polynya through the massive release of heat from the deep sea $^{2,3}$. While the polynya has aroused continued interest ${ }^{1-9}$, the presence of a fresh surface layer has prevented the recurrence of deep convection there since $1976^{8}$, and it is now largely viewed as a naturally rare event ${ }^{10}$. Here, we present a new analysis of historical observations and model simulations that suggest deep convection in the Weddell Sea was more active in the past, and has been weakened by anthropogenic forcing. The observations show that surface freshening of the southern polar ocean since the 1950s has considerably enhanced the salinity stratification. Meanwhile, among the current generation of global climate models, deep convection is common in the Southern Ocean under pre-industrial conditions, but weakens and ceases under a climate change scenario due to surface freshening. A decline of open ocean convection would reduce the production rate of Antarctic Bottom Waters, with important implications for ocean heat and carbon storage, and may have played a role in recent Antarctic climate change.

Antarctic Bottom Water (AABW) is the coldest, densest and most voluminous ${ }^{11}$ water-mass of the world ocean and its shrinking in recent decades ${ }^{12,13}$ has been linked to deep ocean heat uptake $^{12,14}$. Presently produced on Antarctic continental shelves, AABW is exported northwards to fill the deepest layers of the three oceanic basins and feed the deep branch of the meridional overturning circulation ${ }^{11,15}$. In 1928 , based on early hydrographic observations, Wüst ${ }^{16}$ suggested that open ocean convection also contributes to the production of $\mathrm{AABW}$, as it does to North 
Atlantic Deep Water in the Labrador Sea. He argued that deep convection occurred within the Weddell Gyre, but because of difficulty monitoring the Weddell Sea during austral winter, his contention went unverified until the mid-1970s ${ }^{6}$.

Microwave observing satellites were first launched in December 1972, providing global observations of sea ice, and soon thereafter revealed the presence of a $250,000 \mathrm{~km}^{2}$ ice-free area within the seasonally ice-covered Weddell Sea ${ }^{1}$ (Fig. 1a). The huge polynya, located near Maud Rise $\left(65^{\circ} \mathrm{S}, 0^{\circ} \mathrm{E}\right)$, reappeared during the winters of 1974 through 1976 , slowly drifting westward with the background flow ${ }^{1}$. The polynya was maintained by vigorous convective mixing, whereby the upward flux of relatively warm deep waters supplied enough heat to prevent sea ice formation $^{1-3}$. Heat loss at the surface drove cooling to depths of about $3000 \mathrm{~m}$, producing new deep waters $^{3}$ that could have fed the observed surge in Southern Ocean AABW volume during the following decade ${ }^{13}$. Together with the inference from hydrographic data of a Weddell convective event circa $1960^{3}$, these observations confirm that deep convection in the open Weddell Sea has been a significant mode of AABW ventilation ${ }^{5,6}$. However, following 1976, no similar polynya has been observed. The continuing quiescence over the past 37 of 41 available years of satellite observation makes it tempting to assume that deep convection in the open Southern Ocean occurs rarely, with little global consequence. Here we propose, instead, that deep convection was more common in the pre-industrial state, but that the hydrological changes associated with global warming ${ }^{17-19}$ are now suppressing this convective activity.

The high latitude Southern Ocean is weakly stratified, with a cold, fresh surface layer overlying a warmer, saltier interior of nearly identical density ${ }^{6,20}$. Weddell Sea convection is thought to occur when the weak stratification is overcome by low-frequency variability in precipitative- 
evaporative fluxes $^{8,21}$, brine rejection during sea ice formation ${ }^{2}$, or circulation-topography interactions ${ }^{7,20}$. Wind variability may participate in polynya initiation through spin-up of the cyclonic gyre, enhancing Ekman upwelling at the gyre centre and uplift at Maud Rise ${ }^{20}$, or by dynamically ${ }^{9}$ and thermodynamically ${ }^{4}$ weakening the ice pack. Thermobaric effects, which cause the cold surface waters to become relatively denser as they sink, abruptly extend the depth of convective overturning once it begins ${ }^{22}$. Deep convective mixing may continue until an excessive surface freshwater supply ${ }^{2,23}$ or the exhaustion of the deep heat reservoir ${ }^{23}$ allows column restratification.

It has been suggested that a persistent positive phase in the Southern Annular Mode (SAM), brought on by stratospheric ozone depletion and rising $\mathrm{CO}_{2}$ concentrations, may be delaying the return of the Weddell Polynya by inhibiting the reestablishment of the dry atmospheric conditions and associated high surface salinities favourable for destabilizing the winter halocline ${ }^{8}$. But given that increasing inputs of freshwater to the southern high latitude ocean over the last 50 years are well-documented ${ }^{17-19}$, a long-term, large-scale upper-ocean stratification trend could be expected to be superimposed on interannual and decadal variability. To evaluate this possibility, we examined 20,000 profiles of salinity and temperature selected to lie within the southern polar ocean, south of the Antarctic Circumpolar Current, but excluding the Antarctic continental shelf (see Methods) (Fig. 2a). Despite the historically sparse data coverage, significant circumpolar, area-averaged surface freshening over the last 60 years is detected (Fig. 2b). As the surface layer has become more buoyant, both vertical salinity and temperature gradients have intensified (Fig. 2c,d). Because of the strong salinity control on density at the prevailing near-freezing temperatures, the salinity contribution to the density stratification dominates, resulting in increased stability (Fig. 2e). This long-term freshening of southern polar surface waters is 
consistent with changes in the precipitation-evaporation balance related to global water cycle amplification $^{17}$ and the positive SAM trend ${ }^{8,18}$, and with accelerating melting and calving of Antarctic glaciers ${ }^{19}$.

To explore the potential sensitivity of open-ocean deep convection to Southern Ocean freshening under anthropogenic climate change, we examined 36 models of the most recent Coupled Model Intercomparison Project (CMIP5) ${ }^{24}$. Although these models lack fully interactive land ice and cannot simulate increased glacial melt in response to ocean warming (see Supplementary Information), they simulate changes in precipitation, evaporation, winds, sea ice, and ocean circulation. Twenty-five models were found to display significant deep ( $>2000 \mathrm{~m})$ open-ocean convection between $90^{\circ} \mathrm{S}$ and $55^{\circ} \mathrm{S}$ under pre-industrial conditions (see Methods). We stress here the caveat that these global climate models are too coarse to capture the export of dense shelf waters along the continental slope, and therefore miss this important source of deep ocean ventilation $^{10}$. The lack of downslope currents could cause the Southern Ocean to be too weakly stratified, making it more prone to convective activity. Consequently, the simulated convection may be unrealistically strong in some cases, with reduced sensitivity to freshwater loading. On the other hand, the fact that convective chimneys have been clearly observed in the Weddell $\mathrm{Sea}^{3,5,6}$ implies that the non-convecting models are missing a real mode of Southern Ocean ventilation. Indeed, models with no convective activity more often have overly-strong vertical stratification, excessive summer ice coverage, or both ${ }^{10}$ (Supplementary Fig. S3).

The areal extent of convection averages $930,000 \mathrm{~km}^{2}$ over pre-industrial control years across the 25 convecting models. The Weddell and Ross Gyres generally host most of the deep convection, but some models also place convective chimneys in the Indian and Eastern Pacific sectors 
(Supplementary Fig. S1). Fig. 1 (b,c) shows the spatial pattern of convection simulated by two models, chosen for their accurate simulations of AABW properties ${ }^{10}$ and extended climate change experiments (continuing to 2300), that provide among the best qualitative representations of the Weddell Polynya in size, location and intensity of the deep convection. The frequency of convective events is variable across models (Supplementary Table S1 and Fig. S2), reflecting the sensitivity of convection to features of ocean circulation, air-sea fluxes, sea ice ${ }^{23}$, and model resolution ${ }^{25}$. Eleven of the models simulate convection almost every winter, whereas multiple decades can separate convective events in some weakly convecting models. By averaging over the 25 -model ensemble, we find that $63 \%$ of all model years exhibit deep convection in the Southern Ocean, with a mean spacing between convective events of 10 years.

When subjected to increasing $\mathrm{CO}_{2}$ concentrations following historical and RCP8.5 forcings (see Methods), all convecting models show a decrease in the strength of deep convection over the course of years 1900 to 2100 (Fig. 3 and Supplementary Table S2), with seven models displaying a complete cessation before 2030 (Supplementary Table S1). Simulations continued to year 2300 show no return of deep convection over this period. The fact that the slowing of Southern Ocean ventilation is so common across models suggests that a shared process is hampering the development of deep convective chimneys under warming conditions.

To explore the mechanisms driving the shutdown of convection under RCP8.5, we performed additional climate change experiments with a model (CM2Mc) featuring strong, episodic Weddell Sea ventilation events ${ }^{21}$. In a three-member ensemble using this model (see Supplementary Information), the final convection events ended in years 1952, 1987 and 2005, highlighting the intrinsic variability and sensitivity to initial conditions of the convection cycles. 
Enhanced freshwater input south of $45^{\circ} \mathrm{S}$, driven by increased precipitation and decreased evaporation (Supplementary Fig. S4), contributes to strengthening the halocline, building an efficient barrier to convective mixing. In order to test the role of the surface freshwater balance versus that of wind stress changes on ocean circulation, we made two additional sets of simulations with CM2Mc: one three-member ensemble in which we applied only the precipitation-evaporation changes over $90^{\circ} \mathrm{S}-40^{\circ} \mathrm{S}$ and another in which only global wind stress changes were applied (Supplementary Fig. S5). With the application of the wind stress perturbation alone, convection shifted from the Weddell Sea to the Ross Sea, but there was no significant decrease in overall deep Southern Ocean ventilation (Supplementary Fig. S6). In contrast, the precipitation-evaporation perturbation south of $40^{\circ} \mathrm{S}$ alone was sufficient to stop the deep convection, with the latest convection events ending in years 1977, 1989 and 2021 for each ensemble member. We conclude that the decrease in ventilation of Southern Ocean deep and intermediate waters simulated under RCP8.5 can be explained by altered surface freshwater fluxes at southern high latitudes (Supplementary Fig. S6).

As in CM2Mc and the observational record (Fig. 2), surface freshening of the southern polar ocean is observed in 34 of the 36 CMIP5 models and significantly exceeds unforced multidecadal variability in all but two of these models (Fig. 4a and Supplementary Fig. S7). The resulting increase of salinity stratification causes the model pycnoclines to strengthen (Fig. 4b). On average, the stratification strengthens later and more slowly in convecting models than in nonconvecting models, due in part to the disruption of freshwater build-up at the surface by convective exchange with saltier deep waters. Therefore, any tendency of convective models to overestimate convection likely delays their response to a perturbed freshwater balance in comparison with the real ocean: models with more extensive convection areas generally convect 
further into the $21^{\text {st }}$ century (Supplementary Fig. S8). In addition, since CMIP5 models do not include the additional freshwater input from increased glacial melt, they likely underestimate the rate of freshening under climate warming. Indeed, freshening and stratification rates equivalent to those observed over 1956-2013 are not simulated by the ensemble of convecting models until the first half of the $21^{\text {st }}$ century (Fig. 4), the period when the modeled convection strength undergoes its sharpest decrease (Fig. 3). In short, the CMIP5 model ensemble is consistent with a weakening of deep Southern Ocean convection under anthropogenic change, due to approximately the same degree of surface freshening and stratification as we find in the observational record.

The estimated 2-3 Sv of near-freezing surface waters which ventilated the upper AABW layer of the Weddell Sea during the three observed polynya years ${ }^{3}$ represent a significant addition to the $5.4 \pm 1.7 \mathrm{~Sv}$ of shelf water input to the bottom layer of the Southern Ocean ${ }^{15}$. Hence, a decreased frequency of deep convection would be expected to have slowed AABW production ${ }^{3}$, and could have affected the denser shelf-produced AABW by altering the properties of deep waters involved in its formation and subsequent mixing ${ }^{3,13}$. The recent absence of Weddell Sea convection could thus be contributing to the observed widespread warming and volume loss of $\mathrm{AABW}^{12,13}$.

A regime shift in Southern Ocean deep ventilation would also have had impacts on the air-sea exchange of heat and carbon. The heat release from the Weddell Polynya over 1974-1976 was estimated to be $0.4 \times 10^{21} \mathrm{~J}_{\text {per year }}{ }^{3}$, nearly $10 \%$ of the average annual rise in ocean heat content over the 1972-2008 period $^{26}$. Hence, stratification in the Weddell Sea may have increased ocean heat storage and attendant thermosteric sea level rise, and slowed warming of the atmosphere. Indeed, it has been suggested that decelerations of global warming are related to increased deep 
ocean heat storage, with a role for reduced AABW formation ${ }^{14}$. The recent absence of deep openocean convection could be contributing to contemporary trends in Southern Hemisphere climate, including slowed surface warming, subsurface ocean warming, sea ice expansion and polewardintensifying surface westerlies ${ }^{25}$. Additionally, by exchanging with the vast deep ocean carbon pool, Weddell convective events would have modified atmospheric $p \mathrm{CO}_{2}$. It is possible that Southern Ocean deep convection also varied significantly during past, natural climate changes, such as on centennial timescales of recent millennia ${ }^{25}$ and during the last deglaciation, when proxies suggest marked ventilation changes in the deep South Atlantic ${ }^{27}$. Further proxy studies from the Weddell Sea may be able to shed light on these possibilities.

\section{Methods:}

Observational record. All profiles were taken from the latest version of the BLUELink Ocean Archive $^{28}$. We also used salinity and temperature monthly climatologies from the CSIRO Atlas of Regional $\operatorname{Seas}^{28}$ (CARS 2009), which is built from the same database. We first selected profiles with sufficient depth coverage for which the 0-1500 m dynamic height is less than the CARS monthly minimum within Drake Passage (5.1 - 5.7 dyn dm). This dynamic height criterion allows a focus on profiles south of the Antarctic Circumpolar Current. To optimize the use of the relatively sparse data, an equivalent 0-500 m dynamic height threshold (2.2 - $2.6 \mathrm{dyn} \mathrm{dm})$ was determined using the strong relationship between 0-1500 $\mathrm{m}$ and 0-500 $\mathrm{m}$ dynamic heights, as obtained from a simple linear regression. This enabled us to include additional profiles covering only the $0-500 \mathrm{~m}$ depth range.

Salinity, in-situ temperature, and surface-referenced potential density were averaged over 0-100 $\mathrm{m}$ and 100-200 $\mathrm{m}$ for every profile. The derivatives of potential density with respect to salinity and temperature are also calculated and averaged over 0-200 $\mathrm{m}$ to obtain the individual 
contributions of salinity and temperature to the vertical density gradient. To avoid the aliasing of spatial and seasonal variability, we subtract the appropriate monthly gridded $\left(0.5^{\circ} \times 0.5^{\circ}\right) \mathrm{CARS}$ atlas values from the $0-100 \mathrm{~m}$ and $100-200 \mathrm{~m}$ profile means. Yearly anomalies are then constructed as area-weighted averages over the sampled monthly, $0.5^{\circ}$ x $0.5^{\circ}$ bins. We finally add the CARS climatological annual mean to the yearly anomalies to obtain the annual mean time series of Fig. 2. Standard errors are obtained from the standard deviation across sampled bins within each year (July to June), scaled by the square root of their number. Note that years with less than 20 sampled bins were discarded, resulting in quasi-continuous coverage from 1956 onwards.

CMIP5 archive. We analysed all CMIP5 models for which 'piControl', 'historical' and 'rcp85' experiments with potential temperature, salinity and sea ice concentration monthly fields were available. Model outputs were downloaded from the Program for Climate Model Diagnosis and Intercomparison data portal ${ }^{24}$ at http://pcmdi9.1lnl.gov/esgf-web-fe/. A listing of all analysed models along with details on their numerical treatment of oceanic convection is given in Supplementary Table S3.

Pre-industrial control runs use fixed boundary conditions, held at the 1860 level. Historical experiments include the full range of natural and anthropogenic forcings, consistent with observations. RCP8.5, or Representative Concentration Pathway 8.5, corresponds to a high emissions scenario that includes time-varying greenhouse gas, stratospheric ozone, anthropogenic aerosols, and solar forcings. Under RCP8.5, the radiative forcing relative to pre-industrial conditions rises continuously to reach about $8.5 \mathrm{~W} \cdot \mathrm{m}^{-2}$ in 2100 , and increases for another 150 years in the $22^{\text {nd }}-23^{\text {rd }}$ century extension before stabilizing at approximately $12 \mathrm{~W} \cdot \mathrm{m}^{-2}$.

Only one run ('r1i1p1') per model and per experiment was considered. Available pre-industrial control simulations had lengths ranging between 240 and 1000 years. Historical (1860-2005) and 
RCP8.5 (2006-2100 or 2006-2300) outputs were concatenated to obtain the climate change time series. Nine models had extended RCP8.5 integrations (2006-2300).

CMIP5 model output analysis. From monthly salinity and temperature fields, we determined mixed layer depths as the depth $\mathrm{z}$ at which $\sigma_{\theta}(\mathrm{z})-\sigma_{\theta}(10 \mathrm{~m})=0.03 \mathrm{~kg} \cdot \mathrm{m}^{-3}$, where $\sigma_{\theta}$ is the potential density referenced to the surface ${ }^{29}$. This criterion was found to provide a robust diagnostic of modeled mixed layers in the southern polar regions as deep mixed layers were observed to coincide closely with positive sea surface temperature and sea surface salinity anomalies, as well as low sea ice concentration anomalies, signalling the strong vertical flux of heat and salt. Convection area is defined as the total surface area south of $55^{\circ} \mathrm{S}$ with a September mixed layer depth exceeding $2000 \mathrm{~m}$. This depth criterion ensures that only deep convection in the open ocean is taken into account. Convection areas are relatively insensitive to the chosen depth threshold because deep convective overturning was generally observed to extend over most of the water column. September was chosen because maximum convection depths and areas are commonly found at the end of austral winter.

Convective years are defined as years during which the convection area is larger than 100,000 $\mathrm{km}^{2}$ (about a third of the observed 1970s Weddell Polynya area). The 11 models featuring no significant open ocean convection are those that do not simulate any convection area above this threshold (with the exception of MIROC-ESM, which convects during the last 100 years of its 630-year-long control run as a result of drifting deep Southern Ocean densities, but displays no convective activity during the historical period; see Supplementary Table S2).

\section{References:}

1 Carsey, F. D. Microwave observation of the Weddell Polynya. Mon. Weather Rev. 108, 2032-2044 (1980). 
2 Martinson, D. G., Killworth, P. D., Gordon, A. L. A convective model for the Weddell Polynya. J. Phys. Oceanogr. 11, 466-488 (1981).

3 Gordon, A. L. Weddell deep water variability. J. Mar. Res. 40, 199-217 (1982).

4 Parkinson, C. L. On the development and cause of the Weddell Polynya in a sea ice simulation. J. Phys. Oceanogr. 13, 501-511 (1983).

5 Killworth, P. D. Deep convection in the world ocean. Rev. Geophys. 21, 1-26 (1983).

6 Martinson, D. G. in Deep Convection and Deep Water Formation in the Oceans, Chu, P. C., Gascard, J. C. Ed. (Elsevier Oceanography Series, Amsterdam, The Netherlands, 1991), pp. 37-52.

7 Holland, D. M. Explaining the Weddell Polynya - a large ocean eddy shed at Maud Rise. Science 292, 1697-1700 (2001).

8 Gordon, A. L., Visbeck, M., Comiso, J. C. A possible link between the Weddell Polynya and the Southern Annular Mode. J. Clim. 20, 2558-2571 (2007).

9 Hirabara, M., Tsujino, H., Nakano, H., Yamanaka, G. Formation mechanism of the Weddell Sea Polynya and the impact on the global abyssal ocean. J. Oceanogr. 68, 771796 (2012).

10 Heuzé, C., Heywood, K. J., Stevens, D. P., Ridley, J. K. Southern Ocean bottom water characteristics in CMIP5 models. Geophys. Res. Lett. 40, 1409-1414 (2013).

11 Johnson, G. C. Quantifying Antarctic Bottom Water and North Atlantic Deep Water volumes. J. Geophys. Res. 113, C05027 (2008).

12 Purkey, S. G., Johnson, G. C. Global contraction of Antarctic Bottom Water between the 1980s and 2000s. J. Clim. 25, 5830-5844 (2012).

13 Azaneu, M., Kerr, R., Mata, M. M., Garcia, C. A. E. Trends in the deep Southern Ocean (1958-2010): implications for Antarctic Bottom Water properties and volume export. $J$. 
Geophys. Res. 118, 4213-4227 (2013).

14 Meehl, G. A., Hu, A., Arblaster, J. M., Fasullo, J. T., Trenberth, K. E. Externally forced and internally generated decadal climate variability associated with the Interdecadal Pacific Oscillation. J. Clim. 26, 7298-7310 (2013).

15 Orsi, A. H., Smethie Jr, W. M., Bullister, J. L. On the total input of Antarctic waters to the deep ocean: a preliminary estimate from chlorofluorocarbon measurements. J. Geophys. Res. 107, 3122-3135 (2002).

16 Wüst, G. Der Ursprung der Atlantischen Tiefenwasser. Gesellsch.f. Erdkunde, Zeitschrift, 409-509 (1928).

17 Durack, P. J., Wijffels, S. E., Matear, R. J. Ocean salinities reveal strong global water cycle intensification during 1950 to 2000. Science 336, 455-458 (2012).

18 Fyfe, J. C., Gillett, N. P., Marshall, G. J. Human influence on extratropical Southern Hemisphere summer precipitation. Geophys. Res. Lett. 39, L23711 (2012).

19 Rignot, E., Jacobs, S., Mouginot, J., Scheuchl, B. Ice-shelf melting around Antarctica. Science 341, 266-270 (2013).

20 Gordon, A. L., Huber, B. A. Southern Ocean winter mixed layer. J. Geophys. Res. 95, 11655-11672 (1990)

21 Galbraith, E. D. et al. Climate variability and radiocarbon in the CM2Mc Earth System Model. J. Clim. 24, 4230-4254 (2011).

22 Akitomo, K. Open-ocean deep convection due to thermobaricity: 1. Scaling argument. $J$. Geophys. Res. 104, 5225-5234 (1999).

23 Martin, T., Park, W., Latif, M. Multi-centennial variability controlled by Southern Ocean convection in the Kiel Climate Model. Clim. Dyn. 40, 2005-2022 (2013).

24 Taylor, K. E., Stouffer, R. J., Meehl, G. A. An overview of CMIP5 and the experiment 
design. Bull. Am. Meteorol. Soc. 93, 485-498 (2012).

25 Latif, M., Martin, T., Park, W. Southern Ocean sector centennial climate variability and recent decadal trends. J. Clim. 26, 7767-7782 (2013).

26 Church, J. A. et al. Revisiting the Earth's sea-level and energy budgets from 1961 to 2008. Geophys. Res. Lett. 38, L18601 (2011).

27 Burke, A., Robinson, L. F. The Southern Ocean's role in carbon exchange during the last deglaciation. Science 335, 557-561 (2012).

28 Ridgway, K. R., Dunn, J. R., Wilkin, J. L. Ocean interpolation by four-dimensional weighted least squares - application to the waters around Australasia. J. Atmos. Oceanic Technol. 19, 1357-1375 (2002).

29 de Boyer Montégut, C., Madec, G., Fischer, A. S., Lazar, A., Iudicone, D. Mixed layer depth over the global ocean: an examination of profile data and a profile-based climatology. J. Geophys. Res. 109, C12003 (2004).

30 Parkinson, C. L., Comiso, J. C., Zwally, H. J. Nimbus-5 ESMR polar gridded sea ice concentrations. September 1974-1976. Boulder, Colorado USA: National Snow and Ice Data Center. (1999, updated 2004).

\section{Acknowledgements}

We thank D. Bianchi for his help with the analysis. This work was supported by the Stephen and Anastasia Mysak Graduate Fellowship in Atmospheric and Oceanic Sciences, by the Natural Sciences and Engineering Research Council of Canada (NSERC) Discovery program, by the Canadian Institute for Advanced Research (CIFAR) and by computing infrastructure provided to

E.D.G. by the Canadian Foundation for Innovation and Compute Canada. R.B. and I.M. were 
funded by grant NOAA-NA10OAR4310092.

\section{Author Contributions}

All authors shared responsibility for writing the manuscript. C.d.L. assembled and analysed observational data and model output. J.B.P. and E.D.G. conceived and supervised the study. I.M., R.B., E.D.G. and J.B.P. designed the CM2Mc experiments. R.B. performed the CM2Mc experiments.

\section{Additional Information}

The authors declare no competing financial interests. Supplementary information accompanies this paper on www.nature.com/natureclimatechange. Reprints and permissions information is available online at http://www.nature.com/reprints. Correspondence and requests for materials should be addressed to casimir.delavergne@gmail.com.

\section{Figure legends:}

Figure 1: Spatial pattern of Southern Ocean deep convection in observations and models. a, Observed 1974-1976 mean September sea ice concentration (\%) from Nimbus-5 ESMR Polar Gridded Sea Ice Concentrations ${ }^{30}$ delineating the Weddell Polynya extent. b, September mixed layer depth (shading) and 25\%,50\% and 75\% September sea ice concentration contours (grey lines) in the MPI-ESM-LR model, averaged over pre-industrial control years during which the convection area exceeds half of its overall maximum. c, Same as b for the HadGEM2-ES model. Deep mixed layers, coinciding with anomalously low sea ice concentrations, are found over an area of comparable size to the Weddell Polynya and in a similar location. The spatial pattern of deep convection in all convective models is presented in Supplementary Fig. S1. 
Figure 2: Southern polar ocean freshening and stratification. a, Spatial distribution (dots) and year of observation (colour) of the 20,613 profiles included in this study. Excluding years with observations in fewer than 20 half-degree grid squares results in quasi-continuous coverage from 1956 onwards (see Methods). Data from the BLUELink Ocean Archive ${ }^{28}$. b,c,d,e, Annual mean ( \pm one standard error, grey), 10-year running mean (red) and linear trend (black) of 0-100 m salinity, halocline strength, thermocline strength and pycnocline strength, respectively. The density stratification $\left(\mathbf{e}, \Delta \sigma_{\theta}\right)$ and its salinity $\left(\mathbf{c}, \frac{d \sigma_{\theta}}{d S} \Delta S\right)$ and temperature $\left(\mathbf{d}, \frac{d \sigma_{\theta}}{d T} \Delta T\right)$ components are calculated as differences between 100-200 m and 0-100 m, and presented with equal vertical range for comparison. Decadal trends with their $95 \%$ confidence intervals are indicated at the bottom.

Figure 3: Southern Ocean $\left(55^{\circ} \mathrm{S}-90^{\circ} \mathrm{S}\right)$ convection area. a, Ensemble mean (black line) and multi-model standard deviation (grey shading) of normalized convection areas in the 25 CMIP5 convecting models. For each model, the area is normalized by the maximum areal extent of convection recorded in the entire simulation. Shown are the last 240 years of pre-industrial control runs followed by historical (1860-2005) and RCP8.5 (2006-2300) simulations. Only eight models were run beyond year 2100. b, Convection area in the MPI-ESM-LR (blue) and HadGEM2-ES (red) models. The Weddell Polynya area ${ }^{1}$ is indicated by the light grey line for comparison.

Figure 4: Southern polar ocean freshening and stratification in CMIP5 models. Ensemble mean (a) 0-100 m salinity and (b) pycnocline strength of 25 convecting (blue) and 11 non-convecting 
(orange) CMIP5 models run over the $21^{\text {st }}$ century with the RCP8.5 scenario. Both are annual means averaged over the area situated south of the Antarctic Circumpolar Current (where the surface dynamic height relative to $1500 \mathrm{~m}$ is less than its minimum within Drake Passage), excluding shelf waters. Shadings correspond to one multi-model standard deviation. The 10-year running mean (red) and linear trend (black) from the corresponding observations shown in Fig. 2 are repeated here for comparison. 
Figure 1

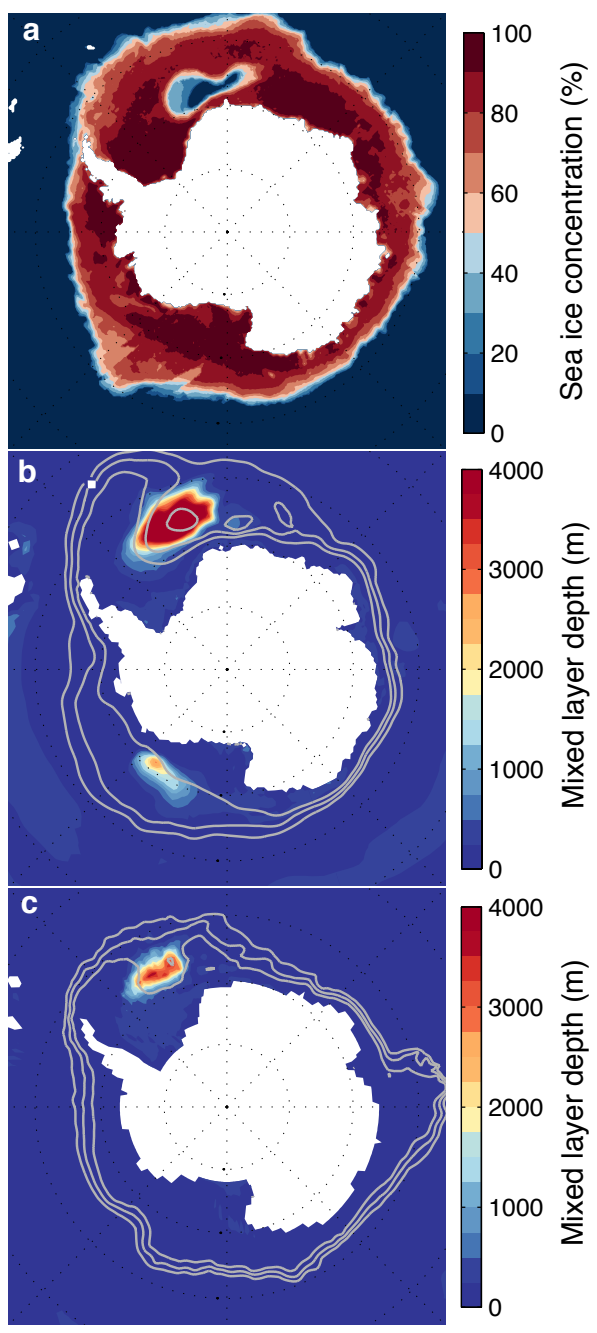


Figure 2
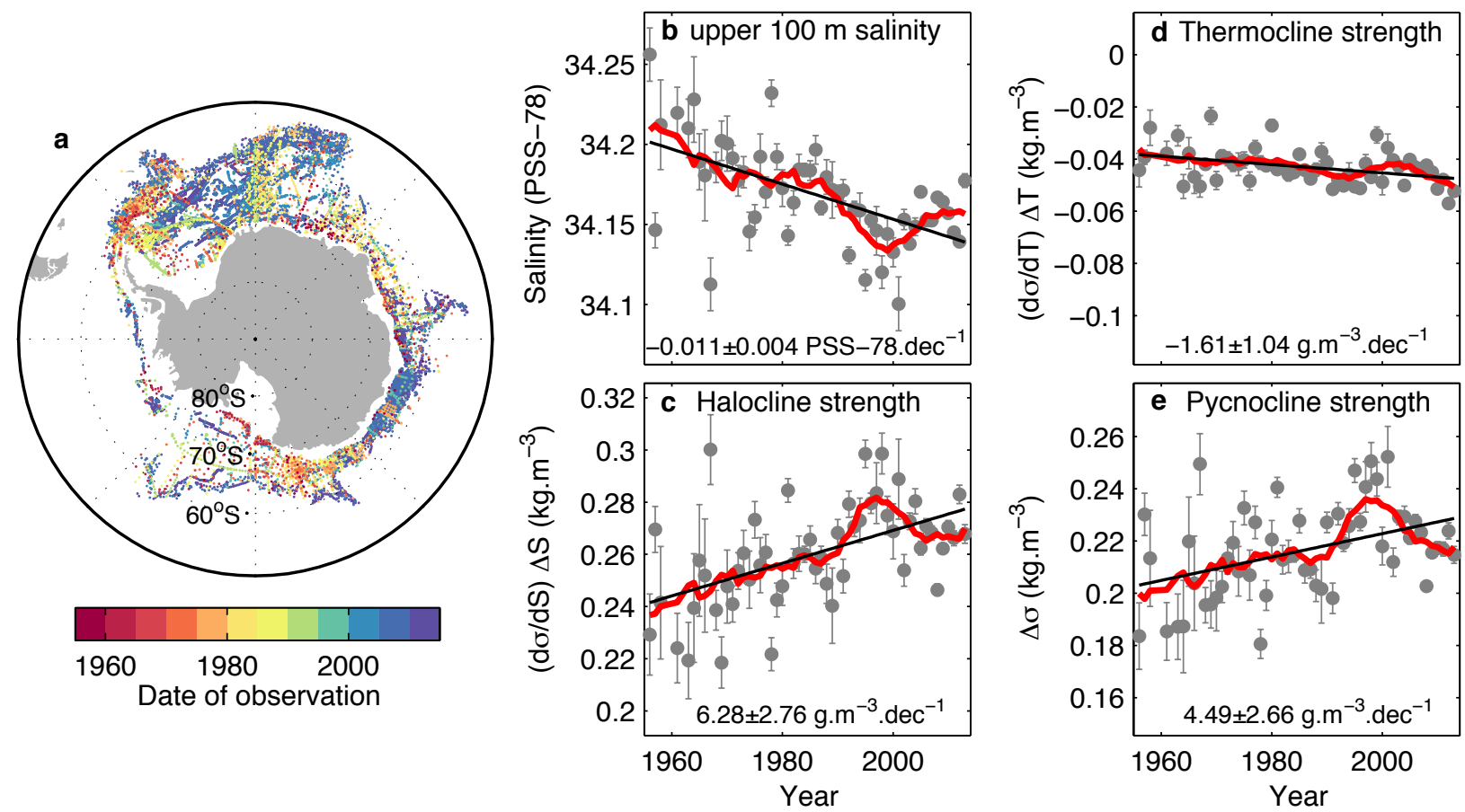
Figure 3
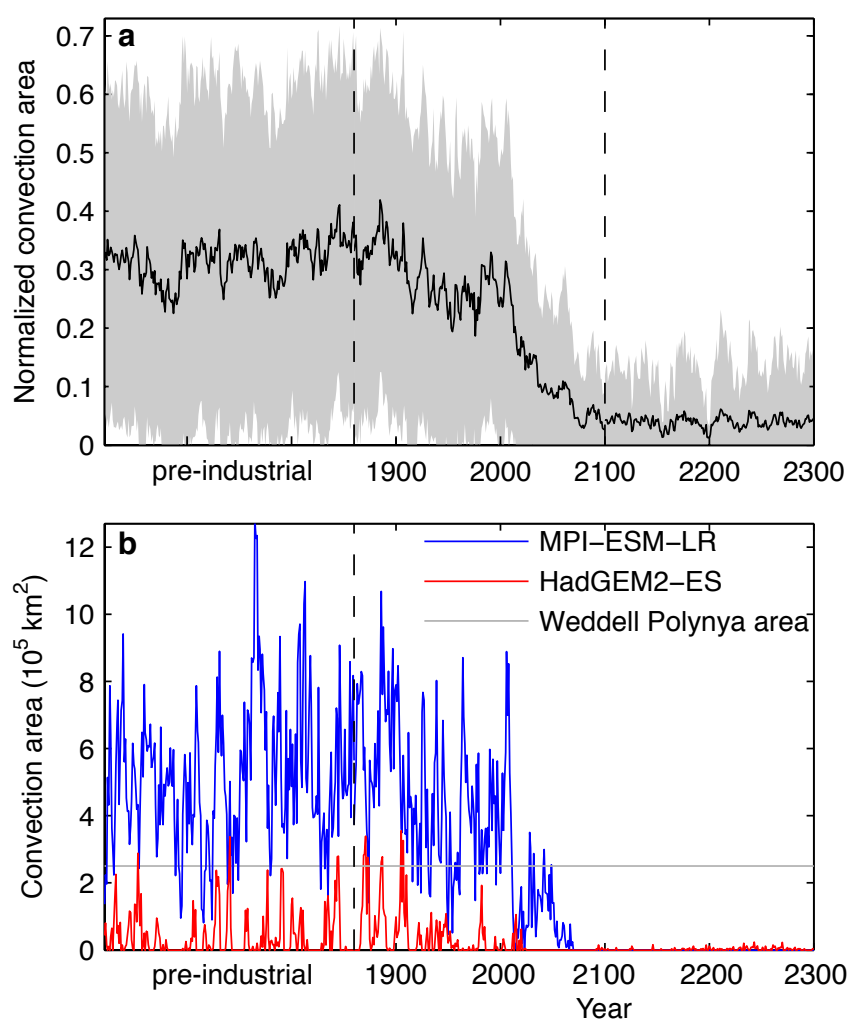
Figure 4

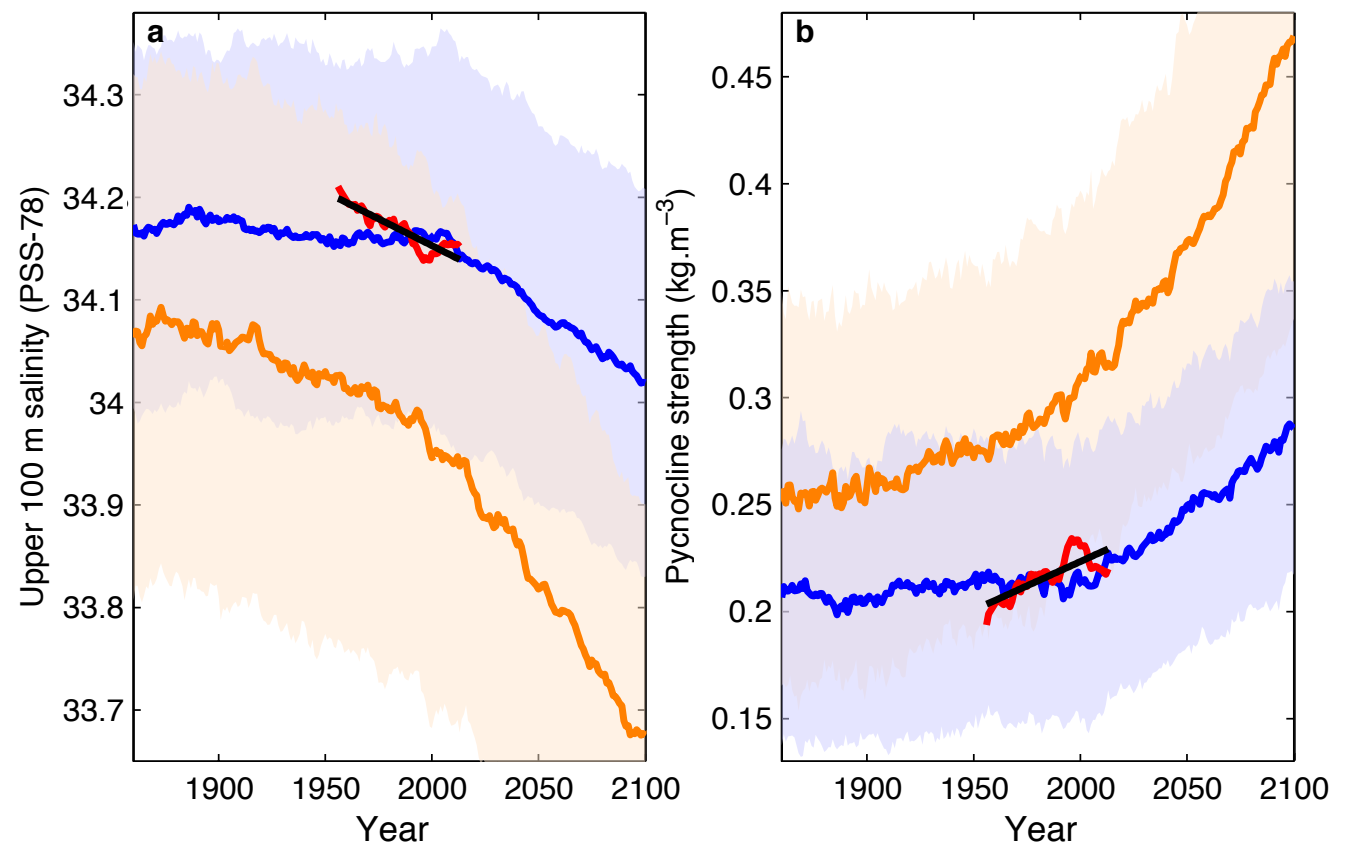


Supplementary Information for:

Cessation of deep convection in the open Southern Ocean under anthropogenic climate change

Casimir de Lavergne, Jaime B. Palter, Eric D. Galbraith, Raffaele Bernardello, Irina Marinov

This pdf file includes:

Supplementary text

Supplementary tables S1-S3

Supplementary figures S1-S8

Supplementary references 


\section{Additional CM2Mc experiments.}

The model used for the additional simulations, $\mathrm{CM} 2 \mathrm{Mc}^{21}$, is a three-degree version of NOAA GFDL's coupled climate model, ESM2M ${ }^{31}$, with a simpler land model (LM2) and excluding the iceberg model ${ }^{32}$. Subgrid-scale oceanic convection is parameterized through enhanced vertical diffusivity (see section 2 and Table S3) within the surface boundary layer scheme, which uses the K-profile parameterization ${ }^{33}$. As described in ref. 34, three ensemble members are run for Climate Change, Wind stress perturbation and Precipitation-evaporation $(P-E)$ perturbation experiments. Each member is started from initial conditions taken 20 years apart from a 1000year pre-industrial simulation segment performed after the end of the spin-up period.

The Climate Change experiments use the historical and RCP8.5 forcing data ${ }^{35}$ recommended by the Coupled Model Intercomparison Project-CMIP524, so that the boundary conditions are identical to those used in 'historical' and 'rcp8.5' CMIP5 experiments. To compute the timevarying perturbation to the wind stress and to the surface freshwater flux used respectively in the Wind stress perturbation and $P-E$ perturbation experiments, we start by running an additional Control simulation, where greenhouse gases are held constant at pre-industrial (1860) levels. We next compute the anomalies in vector wind stress and precipitative-evaporative flux as the differences in monthly means between the Climate Change and Control simulations. In order to remove the interannual signal caused by the main climate modes of variability, we smooth these anomalies by calculating 20-year running means, for each month, over the period 1860-2100. The smoothed anomalies are then applied at each ocean time step, restricted to the $90^{\circ} \mathrm{S}-40^{\circ} \mathrm{S}$ region in the case of the $P-E$ perturbation. In the Wind stress perturbation runs, the wind stress anomalies are applied only when the momentum fluxes are passed from the atmosphere to the 
ocean and do not directly interfere with any other process, including buoyancy forcing calculated with bulk formulae, as in ref. 36. In both ensembles, the atmosphere does not feel the perturbation except for any feedbacks resulting from changes in ocean circulation.

Figures S4, S5, and S6 document the response of the Southern Ocean to the full climate, wind stress only and P-E only forcings. In particular, Figure S5 shows the time evolution of the maximum Southern Ocean zonal mean westerly wind stress as well as latitudinal profiles of the zonally averaged zonal wind stress and P-E flux in all ensemble experiments for the 2070-2100 period. The difference between Climate Change and Control curves gives the wind stress or P-E anomalies applied to the ocean in the Wind stress perturbation and P-E perturbation runs. The Wind stress perturbation experiments exhibit no long-term change in the precipitationevaporation balance, and neither Wind stress perturbation nor P-E perturbation simulations show significant changes in the sea level pressure field (Figure S5). On the other hand, in the Climate Change simulations, both the P-E and sea level pressure meridional contrasts are significantly altered (Figure S5). We note that these simulated changes under RCP8.5 are qualitatively consistent with an amplification of the global water cycle ${ }^{17}$ and a southward shift and intensification of Southern Hemisphere extratropical storm tracks in association with the positive SAM trend ${ }^{18,37}$.

In the Wind stress perturbation ensemble, though the overall ventilation rate of the deep Southern Ocean shows little change (Figure S6), all three members show a migration of the bulk of the deep convection from the Weddell Sea to the Ross Sea. In two of the three members, the last Weddell Sea convection event ends around 2010, and convection establishes almost permanently in the Ross Sea from 2020 onwards. The third member shows some deep 
convection in the Weddell Sea until the end of the simulation, though Ross Sea convection predominates after 2050. The change in the location of deep ventilation arises mainly from a change in ocean circulation: the zonal and meridional wind stress perturbations, which are not zonally homogenous, result in a weakening of the Weddell Gyre's barotropic circulation, but a spin-up of the Ross Gyre. The reduced Ekman upwelling within the Weddell Gyre deepens the pycnocline and increases the stability of the water column there. The opposite is true for the Ross Gyre.

\section{Representation of convective and land ice processes in CMIP5 models.}

Coarse-resolution, hydrostatic CMIP5 models must employ a convective parameterization in order to remove gravitational instabilities through vertical mixing, mimicking the effect of the convective plumes that would rapidly homogenize the water column in nature. These parameterizations have proven efficient in reproducing the gross properties of convective chimneys ${ }^{38}$. Table S3 lists the numerical schemes used in the CMIP5 models included in this study. The most common approach is to increase the vertical diffusivity to very high values (e.g. $\sim 10 \mathrm{~m}^{2} \cdot \mathrm{s}^{-1}$ ) in regions of gravitational instability, also allowing for some mixing below the depth of neutral stability (i.e. penetrative convection). Alternatively, non-penetrative convective adjustment, such as the scheme of ref. 39 , is also frequently used to restore neutral or stable stratification in the water column. Table S3 reveals in particular that the pre-industrial presence or absence of deep convection does not relate to the numerical choices to parameterize open ocean convective processes. 
Land ice, dominated by Antarctic and Greenland ice sheets, is only crudely represented in CMIP5 models. Generally, the treatment of these land-based ice sheets will include a prognostic or prescribed albedo and a simple energy and mass balance scheme that, e.g., transports excess snow accumulating over the continent to the coast as frozen runoff, implying a stable long-term mean ice sheet mass and a closed freshwater cycle ${ }^{32}$. In particular, most models do not explicitly account for the effect of freshwater fed into the ocean through ice-shelf basal melting ${ }^{40}$ and iceberg calving ${ }^{32}$, despite its potential importance for regional freshwater budgets, sea ice cover and deep ocean ventilation ${ }^{32,40-42}$. Some models ${ }^{31}$ now incorporate Lagrangian icebergs ${ }^{32}$ that can realistically redistribute iceberg melt away from the coast. The unresolved ocean-ice shelf interactions ${ }^{43}$ mean, however, that CMIP5 models cannot simulate the observed and projected mass loss of Antarctic ice shelves in response to ocean warming and ocean circulation changes ${ }^{19,41}$. Thus, none of the CMIP5 models analyzed in this study account for changing rates of glacial melt, likely underestimating the rate of freshening of Southern Ocean surface waters under anthropogenic change ${ }^{43,44}$.

\section{Assessment of model drift in CMIP5 Southern Ocean simulations.}

Though reduced when averaged over a large ensemble of models, drift can be significant in individual model simulations, especially in the deep ocean, due to its long equilibration timescale ${ }^{45}$. Therefore, pre-industrial control simulations have been analyzed for drift in Southern Ocean surface and deep water properties. The drift is estimated as the linear trend over the full length of 'piControl' time series ${ }^{45}$, and compared to the 2005-2100 RCP8.5 linear trend (Table S2). Multi-model averages of pre-industrial control and RCP8.5 trends, calculated as the 
mean over statistically significant (at the 95\% level) individual trends, are also given for the convecting and non-convecting model groups.

Table S2 shows that the multi-model mean drift is one to three orders of magnitude smaller than the RCP8.5 trends for all analyzed variables. The drift in convection area averages a gain of $31,000 \mathrm{~km}^{2}$ per century across the convecting models, compared to a multi-model mean decreasing trend of $-384,000 \mathrm{~km}^{2}$ per century for the $1860-2100$ period. Therefore, model drift does not contribute to the slowdown in ensemble mean deep convection documented in Figure 3. Indeed, the small positive ensemble mean drift in both convection area and normalized convection area implies that the decrease in convection strength under RCP8.5 (Figure 3) would only be reinforced if drift were accounted for.

Ensemble mean drift in southern polar ocean 0-100 $\mathrm{m}$ salinity and pycnocline strength is so small that the time series presented in Figure 4 are nearly identical whether linear drift is subtracted from the climate change time series or not. Though insignificant for the ensemble mean, drift can be important for the freshening and stratification of individual models. Therefore, a linear drift was subtracted from the warming-driven trends for each model when constructing Figure S7. This figure shows freshening and stratification during 1860-2100 despite the subtracted drift. The correction mostly affects the GISS-E2-H and CNRM-CM5 models, which have the largest drift-to-trend ratios in upper $100 \mathrm{~m}$ salinity and are the only two models simulating surface salinification of the southern polar ocean over the $21^{\text {st }}$ century. 


\begin{tabular}{|c|c|c|c|c|c|c|c|}
\hline Models & $\begin{array}{r}\text { Maximum } \\
\text { convection } \\
\text { area } \\
\left(10^{5} \mathrm{~km}^{2}\right)\end{array}$ & $\begin{array}{r}\text { Mean } \\
\text { convection } \\
\text { area } \\
\left(10^{5} \mathrm{~km}^{2}\right)\end{array}$ & $\begin{array}{r}\text { Percentage } \\
\text { convective } \\
\text { years } \\
(\%)\end{array}$ & $\begin{array}{r}\text { Mean number } \\
\text { of consecutive } \\
\text { convective } \\
\text { winters }\end{array}$ & $\begin{array}{r}\text { Mean number of } \\
\text { consecutive } \\
\text { non-convective } \\
\text { winters }\end{array}$ & $\begin{array}{r}\text { Maximum } \\
\text { number of } \\
\text { consecutive } \\
\text { non-convective } \\
\text { winters }\end{array}$ & $\begin{array}{r}\text { Latest } \\
\text { convective } \\
\text { year } \\
\text { (historical- } \\
\text { rcp85) }\end{array}$ \\
\hline ACESS1.0 & 18.97 & 10.11 & 100.0 & $\ldots$ & 0.0 & 0 & 2053 \\
\hline ACCESS 1.3 & 22.25 & 8.86 & 93.0 & $\ldots$ & 0.0 & 17 & 2068 \\
\hline BCC-CSM1.1* & 23.08 & 1.87 & 36.2 & 2.5 & 4.3 & 22 & *2125 \\
\hline BCC-CSM1.1m & 32.26 & 8.17 & 66.7 & 7.2 & 3.6 & 45 & 2095 \\
\hline CMCC-CESM & 13.59 & 2.51 & 56.3 & 5.2 & 4.0 & 13 & 2068 \\
\hline СMCC-CM & 13.80 & 3.33 & 57.6 & 11.9 & 8.2 & 24 & 2084 \\
\hline CMCC-CMS & 14.80 & 1.46 & 29.0 & 3.7 & 9.1 & 39 & 1993 \\
\hline CNRM-CM5* & 16.61 & 1.39 & 26.6 & 11.9 & 31.2 & 91 & *2027 \\
\hline CSIRO-Mk3.6* & 2.18 & 0.05 & 1.8 & 2.3 & 98.2 & 161 & *1862 \\
\hline FGOALS-g2 & 2.88 & 0.35 & 6.4 & 1.6 & 21.8 & 110 & 1975 \\
\hline FGOALS-s2 & 51.21 & 37.76 & 100.0 & $\ldots$ & 0.0 & 0 & 2095 \\
\hline GFDL-CM3 & 37.34 & 10.23 & 81.6 & 19.4 & 4.6 & 20 & 2066 \\
\hline GFDL-ESM2G & 35.10 & 14.04 & 99.4 & $\ldots$ & 0.0 & 3 & 2081 \\
\hline GFDL-ESM2M & 21.07 & 8.83 & 96.6 & $\ldots$ & 0.0 & 6 & 2084 \\
\hline GISS-E2-H* & 40.09 & 29.44 & 100.0 & $\ldots$ & 0.0 & 0 & *2295 \\
\hline GISS-E2-R* & 59.03 & 47.55 & 100.0 & $\ldots$ & 0.0 & 0 & *2300 \\
\hline HadGEM2-CC & 7.00 & 0.85 & 30.4 & 2.8 & 6.4 & 17 & 2023 \\
\hline HadGEM2-ES* & 4.13 & 0.49 & 19.8 & 2.0 & 8.1 & 49 & *2015 \\
\hline IPSL-CM5A-LR ${ }^{*}$ & 10.00 & 0.40 & 11.0 & 2.8 & 22.3 & 231 & *2097 \\
\hline IPSL-CM5A-MR & 27.01 & 4.41 & 67.3 & 16.8 & 8.2 & 21 & 2062 \\
\hline IPSL-CM5B-LR & 4.08 & 0.19 & 3.7 & 2.2 & 13.5 & 33 & 2011 \\
\hline MIROC5 & 17.55 & 8.42 & 99.4 & $\ldots$ & 0.0 & 2 & 2100 \\
\hline MPI-ESM-LR ${ }^{*}$ & 13.59 & 5.46 & 99.1 & $\ldots$ & 0.0 & 2 & ${ }^{*} 2051$ \\
\hline MPI-ESM-MR & 19.52 & 8.02 & 100.0 & $\ldots$ & 0.0 & 0 & 2069 \\
\hline MRI-CGCM3 & 28.48 & 17.89 & 100.0 & $\ldots$ & 0.0 & 0 & 2100 \\
\hline CM2Mc & 27.96 & 7.57 & 65.7 & 17.3 & 7.1 & 27 & 1981 \\
\hline BNU-ESM & 0.28 & 0.00 & 0.0 & $\ldots$ & $\ldots$ & $\ldots$ & $\ldots$ \\
\hline CanESM2 & 0.24 & 0.03 & 0.0 & $\ldots$ & $\ldots$ & $\ldots$ & $\ldots$ \\
\hline $\operatorname{ccsm}^{*}$ & 0.24 & 0.00 & 0.0 & $\ldots$ & $\ldots$ & $\ldots$ & $\ldots$ \\
\hline CESM1-BGC & 0.35 & 0.00 & 0.0 & $\ldots$ & $\ldots$ & $\ldots$ & $\ldots$ \\
\hline CESM1-CAM5 & 0.00 & 0.00 & 0.0 & $\ldots$ & $\ldots$ & $\ldots$ & $\ldots$ \\
\hline CESM1-WACCM & 0.09 & 0.00 & 0.0 & $\ldots$ & $\ldots$ & $\ldots$ & $\ldots$ \\
\hline INMCM4 & 0.00 & 0.00 & 0.0 & $\ldots$ & $\ldots$ & $\ldots$ & ... \\
\hline MIROC-ESM & 8.19 & 0.40 & 15.9 & 9.0 & 69.8 & 531 & ... \\
\hline MIROC-ESM-CHEM & 0.00 & 0.00 & 0.0 & $\ldots$ & $\ldots$ & $\ldots$ & $\ldots$ \\
\hline NorESM1-M & 0.03 & 0.00 & 0.0 & $\ldots$ & $\ldots$ & $\ldots$ & $\ldots$ \\
\hline NorESM1-ME & 0.00 & 0.00 & 0.0 & $\ldots$ & $\ldots$ & $\ldots$ & $\ldots$ \\
\hline
\end{tabular}

Table S1: Characteristics of convection in CMIP5 models and CM2Mc.

All metrics were calculated from the full extent of pre-industrial model outputs, except for the latest convective year (last column), which pertains to climate change simulations, extending from 1860 to 2100 or from 1860 to 2300 in nine models (asterisks). The upper 25 models are 
those referred to as 'convecting' models while the bottom 11 models are 'non-convecting' models. Characteristics of convection in CM2Mc are also given for comparison. Despite the significant convection displayed by MIROC-ESM at the end of its control simulation, this model was classified as non-convecting because no single convective year was found in historical and RCP8.5 experiments (see Table S2). Convective years correspond to a convection area in excess of $100,000 \mathrm{~km}^{2}$. Two models (GISS-E2-H and GISS-E2-R) show robust convection until 2300, while seven models cease convecting before 2030 . 


\begin{tabular}{|c|c|c|c|c|c|c|c|c|c|c|}
\hline \multirow[t]{2}{*}{ Models } & \multicolumn{2}{|c|}{$\begin{array}{l}\text { 0-100 m salinity } \\
\text { (PSS-78.cent }^{-1} \text { ) } \\
\end{array}$} & \multicolumn{2}{|c|}{ 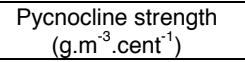 } & \multicolumn{2}{|c|}{$\begin{array}{l}\text { surface density } \\
\left(\mathrm{g} \cdot \mathrm{m}^{-3} \cdot \text { cent }^{-1}\right)\end{array}$} & \multicolumn{2}{|c|}{$\begin{array}{c}2000 \mathrm{~m}^{-3} \text { density } \\
\left(\mathrm{g} \cdot \mathrm{m}^{-3} \cdot \text { cent }^{-1}\right)\end{array}$} & \multicolumn{2}{|c|}{$\begin{array}{l}\text { Convection area } \\
\left(10^{5} \mathrm{~km}^{2} \cdot \text { cent }^{-1}\right) \\
\end{array}$} \\
\hline & piControl & rcp8.5 & piControl & rcp8.5 & piControl & rcp8.5 & piControl & rcp8.5 & piControl & hist-rcp8.5 \\
\hline ACCESS1.0 & -0.001 & -0.158 & 1.0 & 110.9 & -8.1 & -346.3 & -6.2 & -33.1 & 0.25 & -4.68 \\
\hline ACCESS1.3 & 0.007 & -0.226 & -0.2 & 117.8 & 2.1 & -316.1 & 8.5 & -43.9 & -0.82 & -3.95 \\
\hline BCC-CSM1.1 & -0.008 & -0.041 & 0.8 & 35.1 & -5.5 & -243.4 & -4.7 & -23.9 & -0.02 & -0.99 \\
\hline BCC-CSM1.1m & -0.002 & -0.133 & 1.3 & 45.2 & -3.2 & -189.0 & -4.7 & -34.1 & 0.40 & -5.99 \\
\hline CMCC-CESM & -0.005 & -0.138 & 2.9 & 79.6 & -6.8 & -303.1 & -1.5 & -15.7 & -0.23 & -1.25 \\
\hline CMCC-CM & 0.018 & -0.096 & -4.2 & 73.4 & -7.8 & -307.4 & -4.2 & -23.2 & 0.86 & -2.82 \\
\hline CMCC-CMS & 0.000 & -0.066 & -0.7 & 55.9 & 0.0 & -274.4 & -1.3 & -16.9 & 0.17 & -1.13 \\
\hline CNRM-CM5 & -0.022 & 0.013 & 1.7 & 52.5 & -22.4 & -298.8 & -11.1 & -15.5 & 0.00 & -0.86 \\
\hline CSIRO-MK3.6 & -0.001 & -0.267 & 1.9 & 131.3 & -2.0 & -354.6 & 7.6 & -4.3 & -0.02 & -0.05 \\
\hline FGOALS-g2 & 0.027 & -0.164 & 0.1 & 18.9 & 16.3 & -284.7 & 27.5 & -32.5 & 0.01 & -0.26 \\
\hline FGOALS-s2 & 0.012 & -0.456 & 0.8 & 171.1 & 15.9 & -527.8 & 17.5 & -53.7 & 0.35 & -19.71 \\
\hline GFDL-CM3 & 0.004 & -0.211 & 0.0 & 134.3 & -12.4 & -338.3 & -9.5 & -49.9 & 1.61 & -4.53 \\
\hline GFDL-ESM2G & -0.003 & -0.395 & 0.8 & 138.0 & -0.2 & -318.1 & 1.2 & -18.9 & -0.03 & -6.24 \\
\hline GFDL-ESM2M & -0.002 & -0.116 & 0.0 & 64.4 & -3.2 & -196.5 & -2.8 & -21.6 & 0.03 & -5.02 \\
\hline GISS-E2-H & 0.042 & 0.101 & -7.0 & -115.0 & 26.8 & -158.1 & 12.4 & -22.0 & 0.73 & -2.62 \\
\hline GISS-E2-R & 0.001 & -0.123 & -0.1 & 65.0 & -0.1 & -211.3 & 3.0 & -50.2 & -0.50 & -13.69 \\
\hline HADGEM2-CC & -0.001 & -0.293 & -0.3 & 134.3 & 7.0 & -398.2 & -3.0 & -45.2 & -0.02 & -0.35 \\
\hline HADGEM2-ES & -0.006 & -0.244 & 0.4 & 128.7 & -7.4 & -424.1 & -6.1 & -41.9 & -0.03 & -0.44 \\
\hline IPSL-CM5A-LR & 0.001 & -0.066 & -0.6 & 32.3 & 0.2 & -235.6 & -0.5 & -19.0 & 0.07 & 0.21 \\
\hline IPSL-CM5A-MR & -0.002 & -0.079 & 0.2 & 30.7 & -5.6 & -203.9 & 3.4 & -16.1 & 0.30 & -1.12 \\
\hline IPSL-CM5B-LR & 0.014 & -0.096 & -18.3 & 93.6 & 10.6 & -343.2 & -10.0 & -30.8 & 0.15 & -0.10 \\
\hline MIROC5 & 0.003 & -0.164 & 2.7 & 66.4 & -7.0 & -187.1 & -8.7 & -43.6 & 0.30 & -2.88 \\
\hline MPI-ESM-LR & 0.000 & -0.111 & -0.2 & 58.6 & 0.3 & -204.8 & -0.2 & -28.1 & 0.01 & -2.87 \\
\hline MPI-ESM-MR & 0.000 & -0.115 & 0.0 & 78.4 & -0.6 & -171.5 & -0.8 & -27.4 & -0.08 & -3.85 \\
\hline MRI-CGCM3 & 0.004 & -0.086 & -1.1 & 35.4 & 5.1 & -365.3 & -4.2 & -29.9 & 0.46 & -6.74 \\
\hline Multimodel mean & 0.005 & -0.156 & -1.3 & 73.5 & -0.4 & -288.1 & 0.1 & -29.6 & 0.31 & -3.84 \\
\hline CM2Mc & -0.001 & -0.137 & -1.9 & 99.1 & 2.8 & -242.2 & -0.88 & -20.9 & -0.06 & -3.42 \\
\hline BNU-ESM & -0.011 & -0.085 & -7.9 & 58.6 & -1.1 & -352.7 & -18.2 & -40.5 & $\ldots$ & $\ldots$ \\
\hline CanESM2 & -0.003 & -0.338 & 1.9 & 180.7 & -4.8 & -365.8 & 8.3 & -4.9 & $\cdots$ & .. \\
\hline CCSM4 & 0.007 & -0.531 & -1.8 & 303.6 & 2.3 & -448.0 & 5.1 & -24.6 & $\ldots$ & ... \\
\hline CESM1-BGC & 0.006 & -0.411 & 0.1 & 276.3 & -1.1 & -436.4 & 8.1 & -20.1 & $\ldots$ & $\ldots$ \\
\hline CESM1-CAM5 & -0.015 & -0.298 & 4.1 & 231.0 & -10.9 & -447.1 & -4.2 & -22.4 & $\ldots$ & $\ldots$ \\
\hline CESM1-WACCM & 0.013 & -0.387 & 12.7 & 282.8 & -8.3 & -467.2 & 9.6 & -10.0 & $\ldots$ & $\ldots$ \\
\hline INM-CM4 & 0.003 & -0.076 & -4.9 & 56.2 & -1.5 & -216.2 & 12.4 & 2.6 & $\ldots$ & $\ldots$ \\
\hline MIROC-ESM & 0.002 & -0.227 & 1.7 & 157.1 & -14.6 & -283.1 & -30.6 & -48.5 & 0.32 & .. \\
\hline MIROC-ESM-CHEM & -0.029 & -0.198 & 8.7 & 154.2 & -19.3 & -305.1 & -34.5 & -51.9 & $\ldots$ & $\ldots$ \\
\hline NORESM1-M & 0.005 & -0.382 & -0.2 & 75.2 & -5.6 & -358.0 & -2.5 & -31.1 & $\ldots$ & $\ldots$ \\
\hline NORESM1-ME & 0.008 & -0.439 & -3.6 & 85.9 & 3.6 & -351.3 & -4.8 & -25.9 & $\ldots$ & $\ldots$ \\
\hline Multimodel mean & -0.002 & -0.307 & 2.4 & 169.3 & -6.0 & -366.4 & -4.7 & -25.2 & $\ldots$ & $\ldots$ \\
\hline
\end{tabular}

Table S2: Pre-industrial control and RCP8.5 Southern Ocean linear trends in CMIP5 models and CM2Mc.

Upper $100 \mathrm{~m}$ salinity and pycnocline strength refer to southern polar ocean annual means, as presented in Figure 4; surface and $2000 \mathrm{~m}$ density refer to $90^{\circ} \mathrm{S}-50^{\circ} \mathrm{S}$ annual mean locally- 
referenced potential densities; convection area is as defined in Methods and as presented in Figure 3. Full-length pre-industrial control and 2005-2100 (1860-2100 for the convection area) RCP8.5 linear trends are compared. Statistically significant trends at the $95 \%$ level are indicated in bold. Multi-model averages, calculated as the mean over 95\%-level significant trends, are also given for the convecting and non-convecting model groups. Note that differing lengths of 'piControl' time series preclude a direct assessment of the drift (and its significance) in ensemble mean properties. The multi-model mean drift is one to three orders of magnitudes smaller than RCP8.5 trends. All convecting models show a significant decrease in convection area over 1860-2100 except IPSL-CM5A-LR, which shows non-significant change over this period but ceases to convect following 2097 (Table S1). The MIROC-ESM models exhibit the strongest drift in $2000 \mathrm{~m}$ density: warming and freshening of Southern Ocean deep waters gradually weaken the vertical stability, eventually causing the abrupt convective onset at year 530 of the MIROC-ESM pre-industrial simulation (only 255 years are available for MIROC-ESM-CHEM). 


\begin{tabular}{|c|c|c|c|}
\hline Models & Ocean code & Mixed layer scheme & Treatment of convection \\
\hline ACESS1.0 & MOM4.1 & K-profile parameterization (33) & enhanced vertical diffusion \\
\hline ACCESS1.3 & MOM4.1 & K-profile parameterization (33) & enhanced vertical diffusion \\
\hline BCC-CSM1.1 & MOM4-L40 & K-profile parameterization (33) & enhanced vertical diffusion \\
\hline BCC-CSM1.1m & MOM4-L40 & K-profile parameterization (33) & enhanced vertical diffusion \\
\hline CMCC-CESM & NEMO(OPA8.2) & Turbulent kinetic energy closure $(46,47)$ & enhanced vertical diffusion \\
\hline CMCC-CM & NEMO(OPA8.2) & Turbulent kinetic energy closure $(46,47)$ & enhanced vertical diffusion \\
\hline CMCC-CMS & NEMO(OPA8.2) & Turbulent kinetic energy closure $(46,47)$ & enhanced vertical diffusion \\
\hline CNRM-CM5 & NEMO3.2 & Turbulent kinetic energy closure $(46,47)$ & enhanced vertical diffusion \\
\hline CSIRO-Mk3.6 & MOM2.2 & Kraus-Turner scheme (48) & convective adjustment (39) \\
\hline FGOALS-g2 & LICOM2 & Turbulent kinetic energy closure $(49,50)$ & convective adjustment (39) \\
\hline FGOALS-s2 & LICOM2 & Turbulent kinetic energy closure $(49,50)$ & convective adjustment (39) \\
\hline GFDL-CM3 & MOM4.1 & K-profile parameterization (33) & enhanced vertical diffusion \\
\hline GFDL-ESM2G & GOLD & Bulk mixed layer/Turbulent kinetic energy closure $(48,51,52)$ & included in the turbulence closure \\
\hline GFDL-ESM2M & MOM4.1 & K-profile parameterization (33) & enhanced vertical diffusion \\
\hline GISS-E2-H & HYCOM & K-profile parameterization (33) & enhanced vertical diffusion \\
\hline GISS-E2-R & Russell & K-profile parameterization (33) & enhanced vertical diffusion \\
\hline HadGEM2-CC & HadGOM2 & Kraus-Turner/K-theory scheme $(48,33)$ & convective adjustment (39) \\
\hline HadGEM2-ES & HadGOM2 & Kraus-Turner/K-theory scheme $(48,33)$ & convective adjustment (39) \\
\hline IPSL-CM5A-LR & NEMO3.2 & Turbulent kinetic energy closure $(46,47)$ & enhanced vertical diffusion \\
\hline IPSL-CM5A-MR & NEMO3.2 & Turbulent kinetic energy closure $(46,47)$ & enhanced vertical diffusion \\
\hline IPSL-CM5B-LR & NEMO3.2 & Turbulent kinetic energy closure $(46,47)$ & enhanced vertical diffusion \\
\hline MIROC5 & COCO4.5 & Turbulent kinetic energy closure $(53,54,55)$ & convective adjustment (39) \\
\hline MPI-ESM-LR & MPI-OM & Richardson number dependent (56) & enhanced vertical diffusion \\
\hline MPI-ESM-MR & MPI-OM & Richardson number dependent (56) & enhanced vertical diffusion \\
\hline MRI-CGCM3 & MRI.COM3 & Turbulent kinetic energy closure $(53,54,55)$ & convective adjustment (39) \\
\hline $\mathrm{CM} 2 \mathrm{Mc}$ & MOM4.1 & K-profile parameterization (33) & enhanced vertical diffusion \\
\hline BNU-ESM & MOM4.1 & K-profile parameterization (33) & enhanced vertical diffusion \\
\hline CanESM2 & NCOM & K-profile parameterization (33) & enhanced vertical diffusion \\
\hline CCSM4 & POP2 & K-profile parameterization (33) & enhanced vertical diffusion \\
\hline CESM1-BGC & POP2 & K-profile parameterization (33) & enhanced vertical diffusion \\
\hline CESM1-CAM5 & POP2 & K-profile parameterization (33) & enhanced vertical diffusion \\
\hline CESM1-WACCM & POP2 & K-profile parameterization (33) & enhanced vertical diffusion \\
\hline INMCM4 & INMOM4 & Richardson number dependent (56) & enhanced vertical diffusion \\
\hline MIROC-ESM & $\mathrm{COCO} 3.4$ & Turbulent kinetic energy closure $(53,54,55)$ & convective adjustment (39) \\
\hline MIROC-ESM-CHEM & $\mathrm{COCO} 3.4$ & Turbulent kinetic energy closure $(53,54,55)$ & convective adjustment (39) \\
\hline NorESM1-M & MICOM/Bergen & Bulk mixed layer/Turbulent kinetic energy closure (57) & convective adjustment (39) \\
\hline NorESM1-ME & MICOM/Bergen & Bulk mixed layer/Turbulent kinetic energy closure (57) & convective adjustment (39) \\
\hline
\end{tabular}

Table S3: Parameterizations of convection in CMIP5 models and CM2Mc.

The numerical treatment of mixed layer physics and convective instabilities is given for each model along with relevant references (numbers). The algorithm of ref. 39 is indicated as the reference for non-penetrative convective adjustment schemes though some models may use slightly different implementations. Information was collected from the ES-DOC model metadata 
database available at http://earthsystemcog.org/projects/es-doc-models/comparator_demo, complemented by published model documentation. 

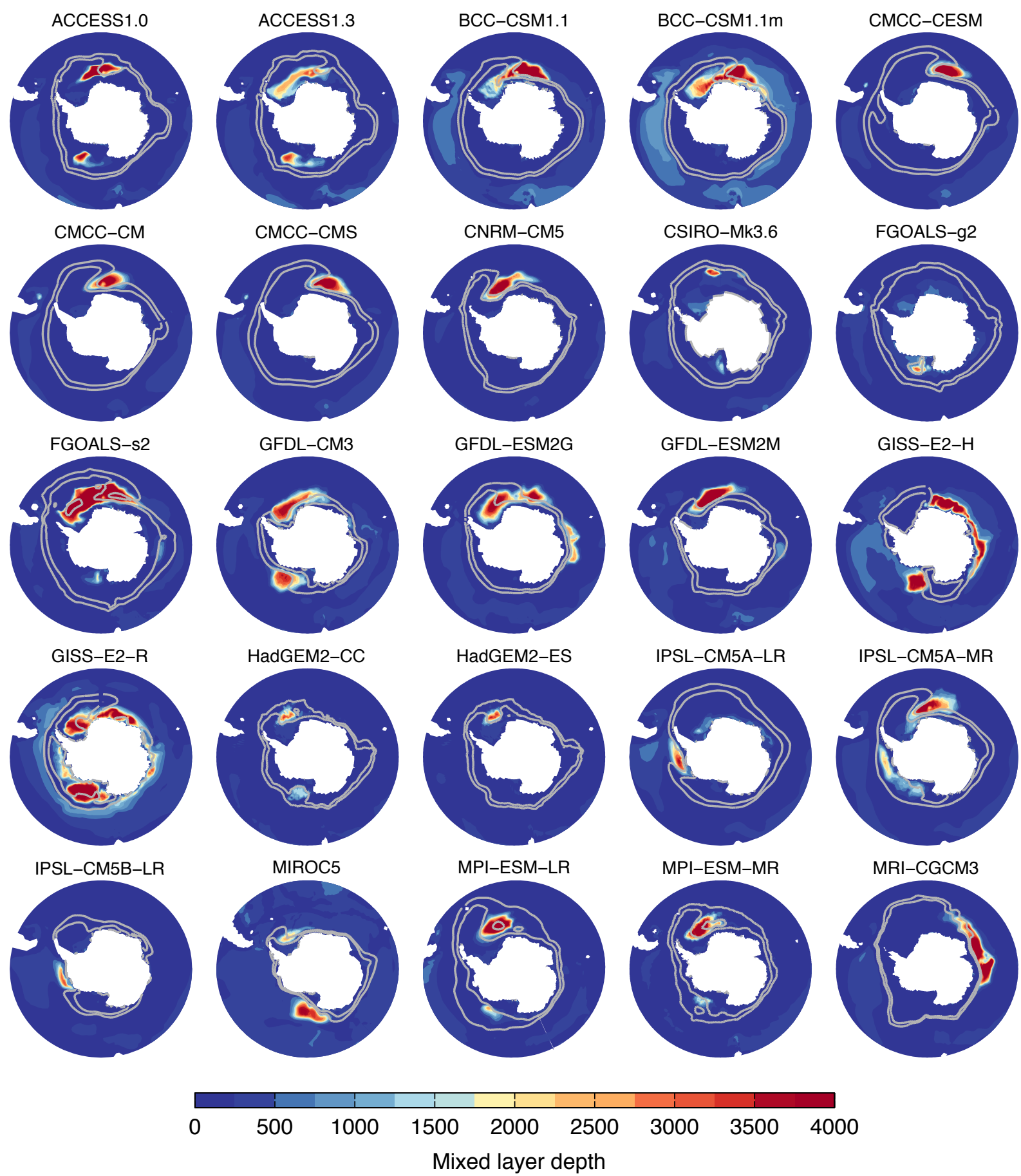

Figure S1: Spatial pattern of Southern Ocean deep convection in 25 convecting CMIP5 models.

For each model, the September mixed layer depth (shading) and 25\% and 75\% September sea ice concentration contours (light grey lines) are shown as averages over pre-industrial control years during which the convection area exceeds half of its overall maximum. 

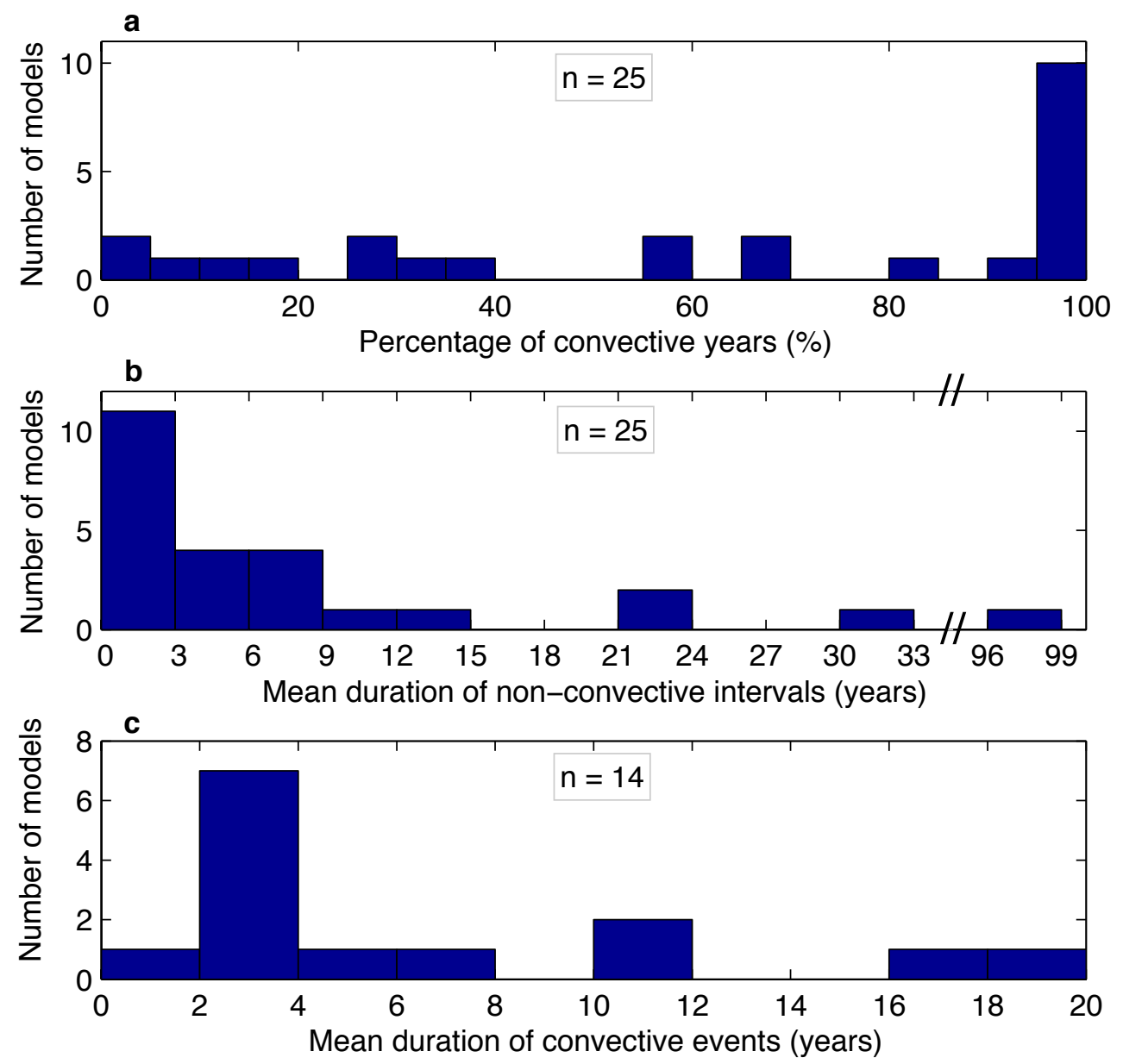

Figure S2: Frequency and duration of simulated Southern Ocean convective events under preindustrial conditions. Distribution of the 25 convecting CMIP5 models according to (a) percentage of convective years and (b) mean duration of non-convective intervals, and (c) distribution of 14 intermittently convecting CMIP5 models according to duration of convection events. Note that both the frequency and the duration of convective events are highly variable across models. Eleven models simulate convection almost every winter. The 14 models that allow only intermittent convection show a mean duration of convective periods ranging between one and 19 consecutive winters, and a mean hiatus between events of three to 98 years. 


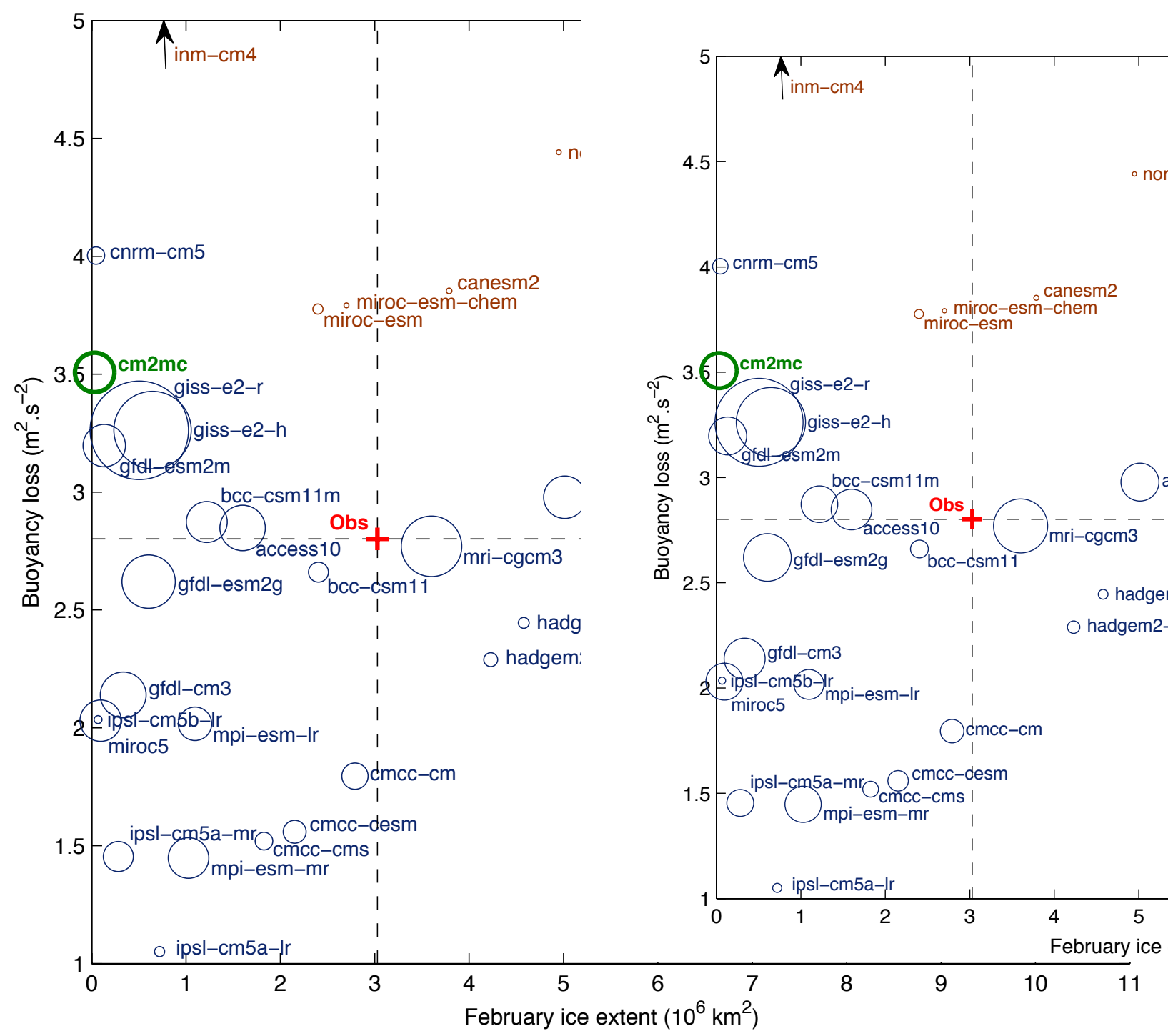

Figure S3: Southern Ocean stratification versus February ice extent in the CMIP5 model suite for the 1976-2005 period. Pre-industrial mean convection area reflected by the size of the circle for each model. The stratification is measured by the buoyancy loss necessary for convection to reach a depth of $3000 \mathrm{~m}$ in September, calculated as $\frac{g}{\rho_{0}} \int_{0}^{3000}\left[\sigma_{\theta}(3000 m)-\sigma_{\vartheta}(z)\right] d z$, averaged over $55^{\circ} \mathrm{S}-90^{\circ} \mathrm{S} ; \sigma_{\theta}$ is the potential density referenced to the surface, and $\mathrm{g}, \rho_{0}$ are constants. Sea ice extent refers to the area over which the sea ice concentration is larger than $15 \%$. All model variables are averaged over 1976-2005. A corresponding observational estimate (red cross) is 
indicated, where the stratification is calculated from the CARS ${ }^{28}$ September climatology and the observed February sea ice extent is the 1979-2005 average (data from the National Snow and Ice Data Center $^{58}$ ). The 11 models with no significant convective activity (brown) tend to have either strong vertical stratification or large summer sea ice coverage or a combination of both relative to observations. The CM2Mc model (three-member ensemble mean) is shown in green. 


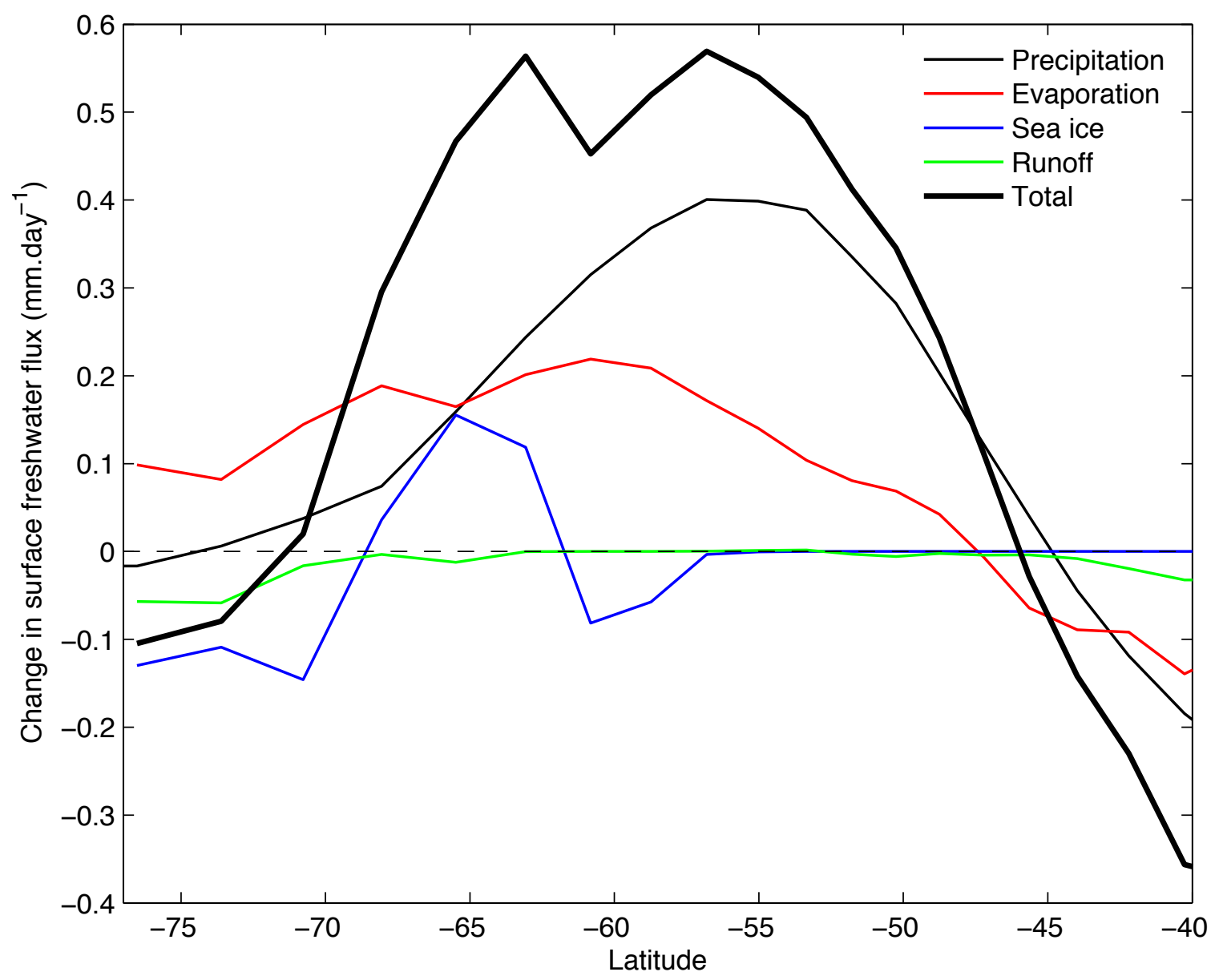

Figure S4: Changes in surface freshwater fluxes $\left(\mathrm{mm}^{-d_{a y}}{ }^{-1}\right)$ in the CM2Mc Climate Change model simulations. Zonal mean total change (thick black line) and contributions due to precipitation (black), evaporation (red), sea ice melt (blue; negative values mean less melt or more ice growth) and runoff (green). Positive values correspond to an increase in freshwater input to the surface ocean. Ensemble multi-annual mean of three simulations presented for years 2070-2100 minus 1860-1890 (the same quantity calculated in the Control simulations showed the model drift to be negligible). Precipitative-evaporative freshening changes dominate between $68^{\circ} \mathrm{S}$ and $46^{\circ} \mathrm{S}$. 

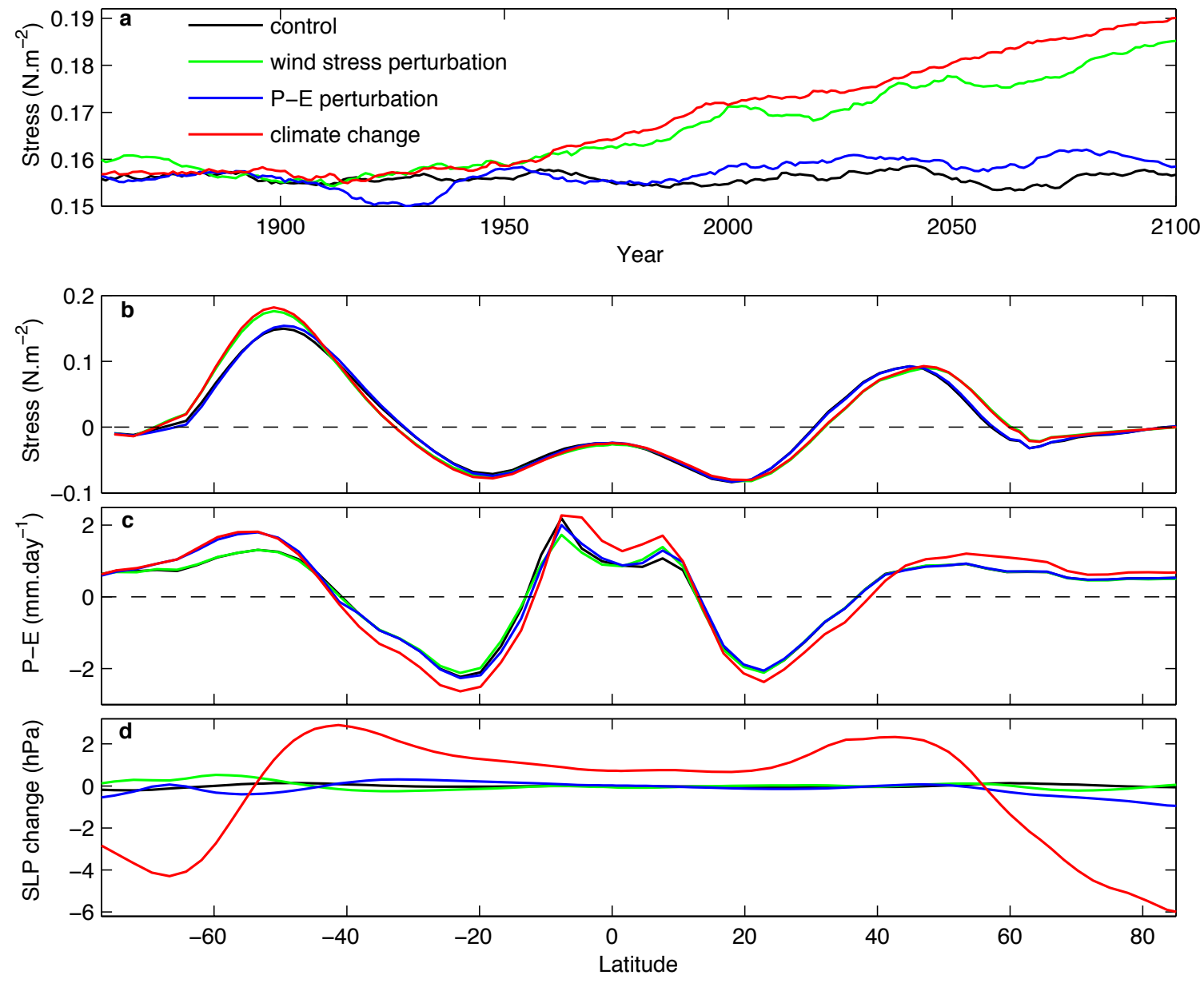

Figure S5: Changes in low-level atmospheric circulation and hydrological cycle in the CM2Mc ensemble experiments. a, Time evolution of the 20-year running mean maximum Southern Ocean zonal mean zonal wind stress. Zonal mean (b) zonal wind stress and (c) precipitation minus evaporation (P-E) averaged over 2070-2100. d, Difference in zonal mean sea level pressure (SLP) between years 2070-2100 and 1860-1890. All are averaged over (black) Control, (green) Wind stress perturbation, (blue) P-E perturbation and (red) Climate Change threemember ensembles. Under RCP8.5 (red curves), the P-E meridional gradients deepen and the high latitude maxima in P-E shift poleward (c). The deepening of the meridional gradient in SLP at about $53^{\circ} \mathrm{S}$ (d) signals the positive long-term change in the SAM index, which is accompanied by a strengthening and southward shift of the low-level atmospheric circulation $(a, b)$. 

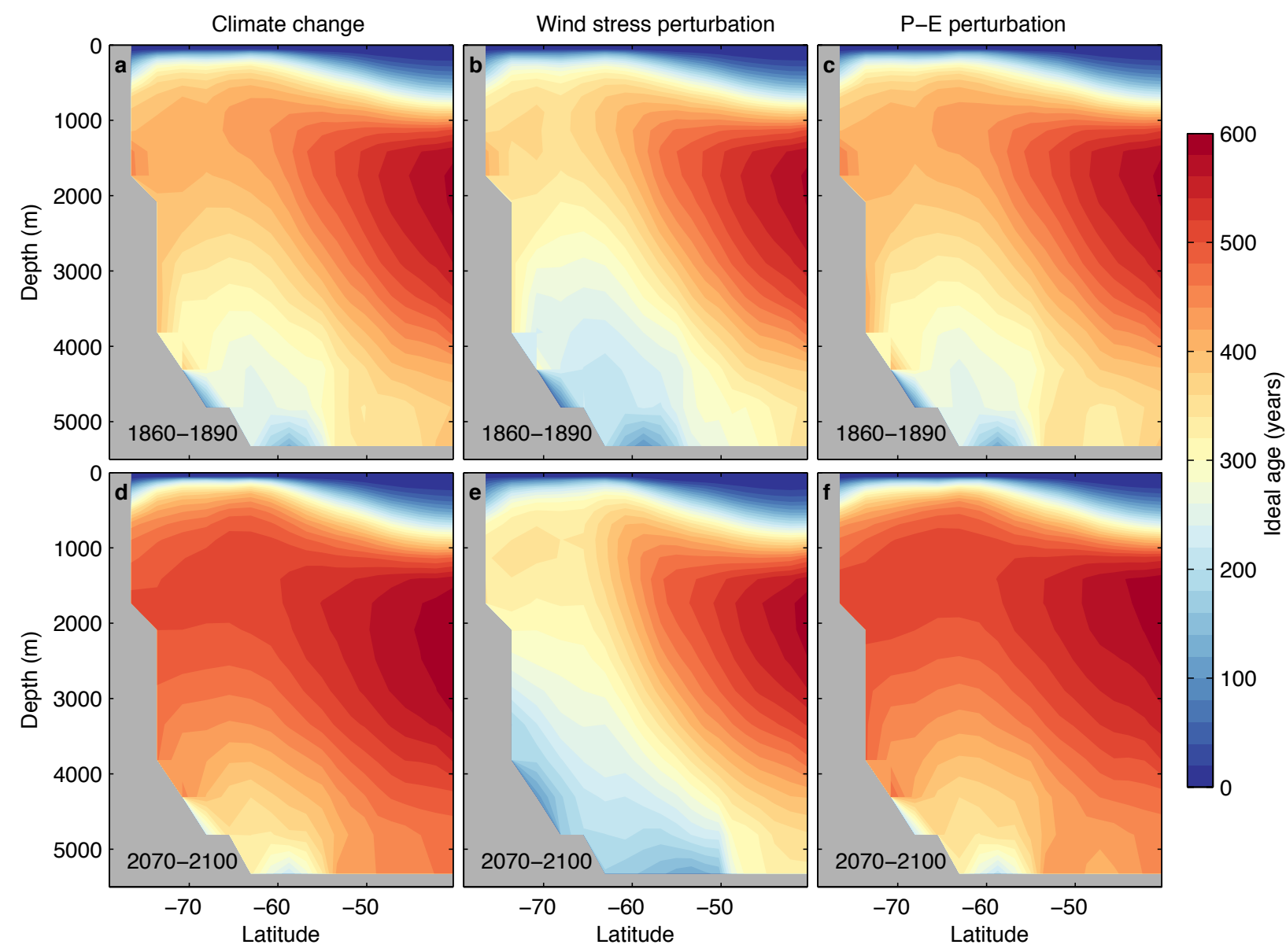

Figure S6: Zonal mean water age (since surface contact) in a depth versus latitude Southern Ocean profile for the CM2Mc model. Ensemble mean of three simulations shown for the 1860-1890 and 2070-2100 periods for the Climate Change (a and d, respectively), Wind stress perturbation (b and $\mathbf{e}$ ) and $P-E$ perturbation ( $\mathbf{c}$ and $\mathbf{f}$ ) experiments. The decrease in ventilation of intermediate and deep waters over 1860-2100 in the climate change experiments is not due to changes in wind stress, and hence must be explained by altered buoyancy fluxes. Changes in precipitation and evaporation south of $40^{\circ} \mathrm{S}$ alone cause a similar ventilation slowdown as that simulated under the full climate change forcing. 


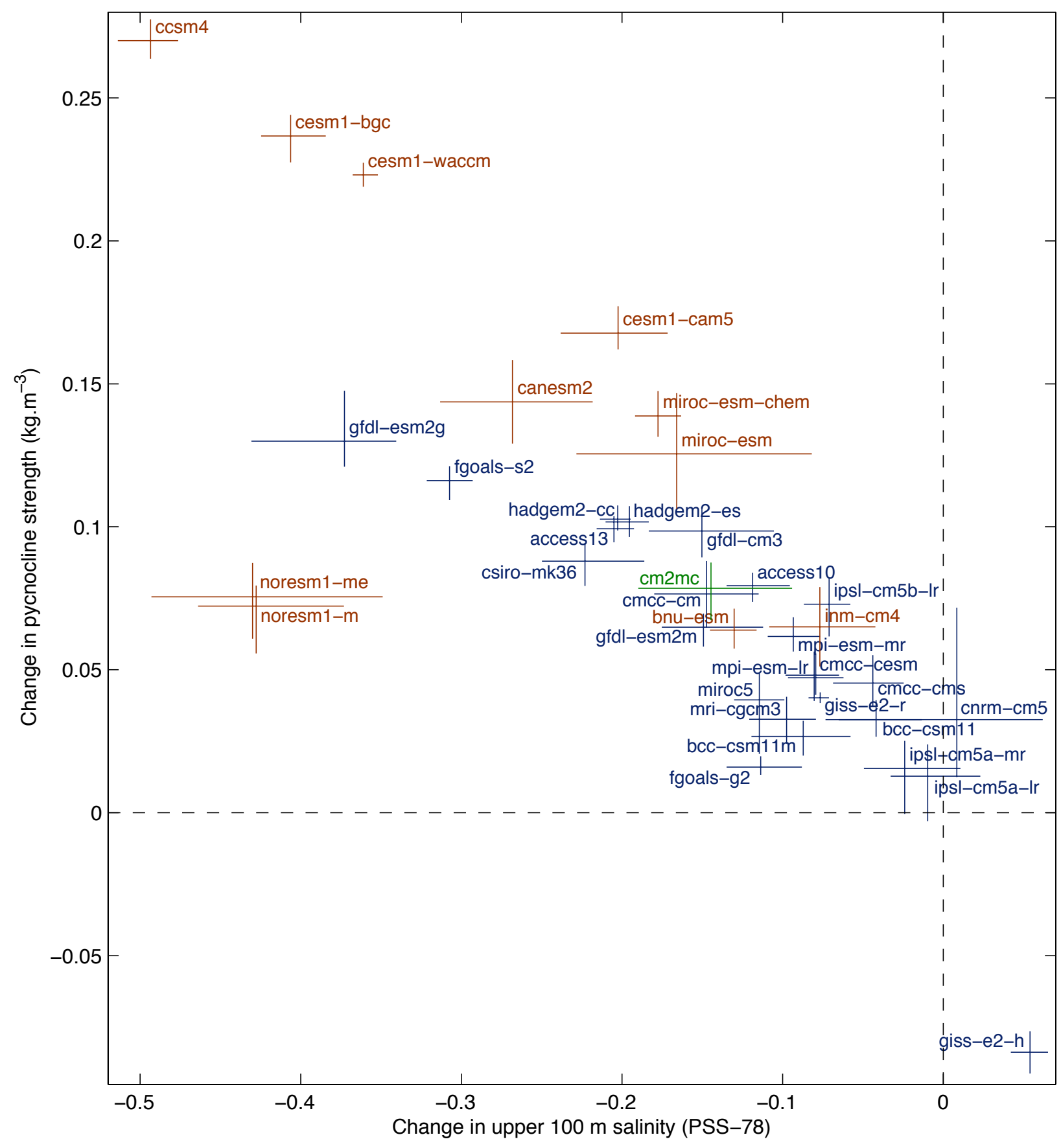

Figure S7: RCP8.5 changes and internal variability in southern polar ocean surface salinity and stratification in the CMIP5 model suite. Variables are annual averages over the region where the surface dynamic height relative to $1500 \mathrm{~m}$ is less than its minimum within Drake Passage, thus excluding both Antarctic Circumpolar Current and shelf waters. RCP8.5 changes (position of 
crosses) refer to years 2050-2100 minus $1860-2005$, and were corrected for drift by subtracting the linear pre-industrial control trends from the climate change time series. The range of unforced multidecadal variability is indicated by the vertical and horizontal bars, whose length is proportional to the maximum anomalies of all 50-year periods from the detrended pre-industrial control mean. Thus, RCP8.5 changes cannot be distinguished from unforced variability whenever these bars cross the origin, which is the case for the CNRM-CM5, IPSL-CM5A-LR and IPSL-CM5A-MR models only. Both convecting (blue) and non-convecting (brown) models are shown. The CM2Mc model ensemble is shown in green. 


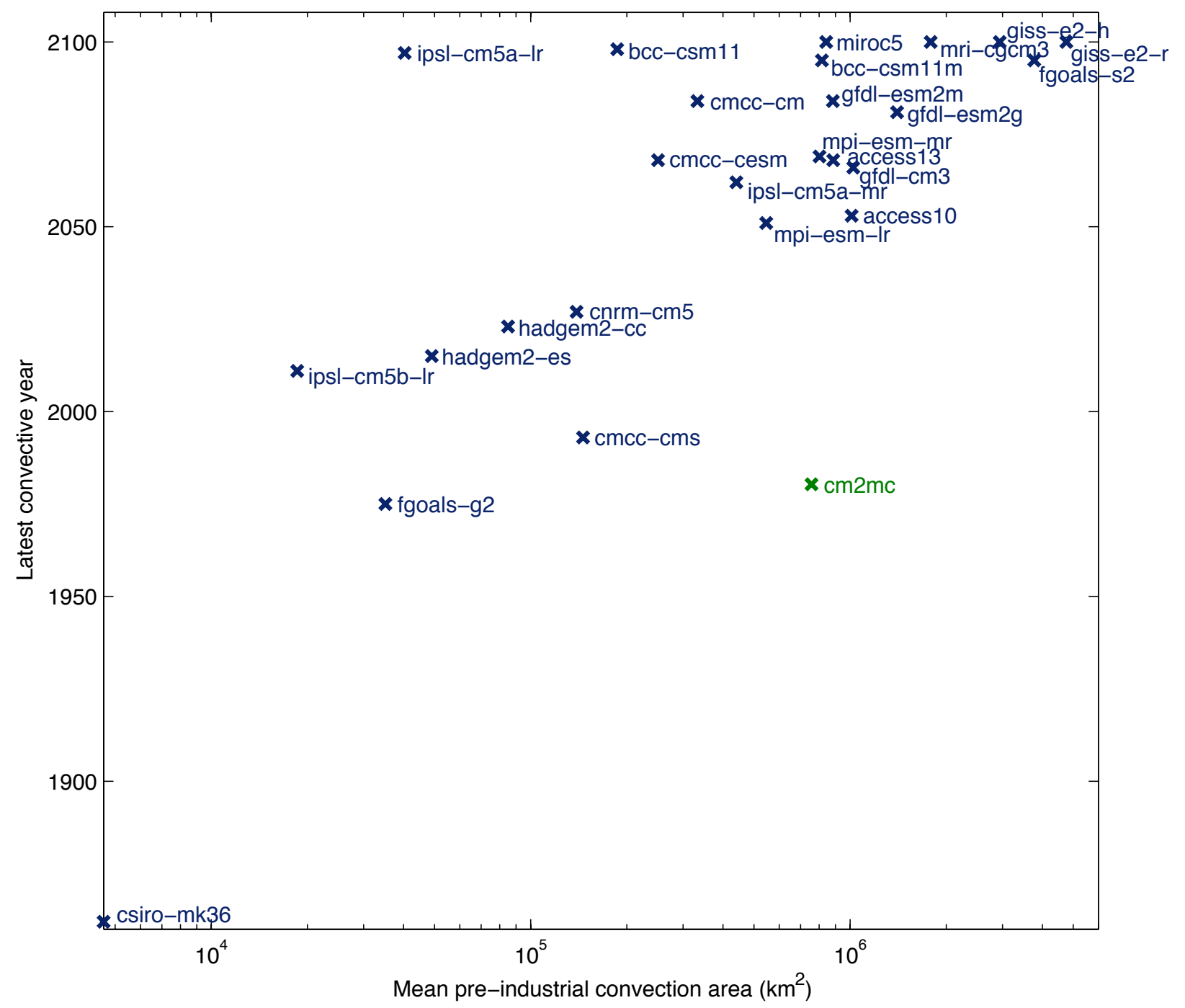

Figure S8: Latest convective year versus mean pre-industrial convection area in the 25 convecting CMIP5 models. Mean pre-industrial area is presented in log scale. The latest convective year corresponds to the last year of the climate change simulation (1860-2100) characterized by a convection area in excess of $100,000 \mathrm{~km}^{2}$. Note that models with large convection areas tend to convect further in the $21^{\text {st }}$ century. The three-member CM2Mc ensemble is shown in green. 


\section{Supplementary references:}

31 Dunne, J. P. et al. GFDL's ESM2 global coupled climate-carbon Earth System Models. Part I: Physical formulation and baseline simulation characteristics. J. Clim. 25, 6646-6665 (2012).

32 Martin, T., Adcroft, A. Parameterizing the fresh-water flux from land ice to ocean with interactive icebergs in a coupled climate model. Ocean Model. 34, 111-124 (2010).

33 Large, W. G., McWilliams, J. C., Doney, S. C. Oceanic vertical mixing: a review and a model with a nonlocal boundary layer parameterization. Rev. Geophys. 32, 363-403 (1994).

34 Bernardello, R. et al. Response of the ocean natural carbon storage to projected $21^{\text {st }}$ century climate change. J. Clim. doi:10.1175/JCLI-D-13-00343.1, in press.

35 Meinshausen, M. et al. The RCP greenhouse gas concentrations and their extensions from 1765 to 2300. Climatic Change 109, 213-241 (2011).

36 Delworth, T. L., Zeng, F. Simulated impact of altered Southern Hemisphere winds on the Atlantic meridional overturning circulation. Geophys. Res. Lett. 35, L20708 (2008).

37 Yin, J. H. A consistent poleward shift of the storm tracks in simulations of $21^{\text {st }}$ century climate. Geophys. Res. Lett. 32, L18701 (2005).

38 Klinger, B. A., Marshall, J., Send, U. Representation of convective plumes by vertical adjustment. J. Geophys. Res. 101, 18175-18182 (1996).

39 Rahmstorf, S. A fast and complete convection scheme for ocean models. Ocean Model. 101, 9-11 (1993). 
40 Hellmer, H. H. Impact of Antarctic ice shelf basal melting on sea ice and deep ocean properties. Geophys. Res. Lett. 31, L10307 (2004).

41 Hellmer, H. H., Kauker, F., Timmermann, R., Determann, J., Rae, J. Twenty-first century warming of a large Antarctic ice-shelf cavity by a redirected coastal current. Nature $\mathbf{4 8 5}$, 225-228 (2012).

42 Silva, T. A. M., Bigg, G. R., Nicholls, K. W. Contribution of giant icebergs to the Southern Ocean freshwater flux. J. Geophys. Res. 111, C03004 (2006).

43 Bintanja, R., van Oldenborgh, G. J., Drijfhout, S. S., Wouters, B., Katsman, C. A. Important role for ocean warming and increased ice-shelf melt in Antarctic sea-ice expansion. Nature Geosci. 6, 376-379 (2013).

44 Helm, K. P., Bindoff, N. L., Church, J. A. Changes in the global hydrological cycle inferred from ocean salinity. Geophys. Res. Lett. 37, L18701 (2010).

45 Sen Gupta, A., Jourdain, N. C., Brown, J. N., Monselesan, D. Climate drift in CMIP5 models. J. Clim. 26, 8597-8615 (2013).

46 Gaspar, P., Grégoris, Y., Lefevre, J-M. A Simple eddy kinetic energy model for simulations of the oceanic vertical mixing: tests at station Papa and Long-Term Upper Ocean Study site. J. Geophys. Res. 95, 16179-16193 (1990).

47 Blanke, B., Delescluse, P. Variability of the tropical Atlantic Ocean simulated by a general circulation model with two different mixed-layer physics. J. Phys. Oceanogr. 23, 1363-1388 (1993).

48 Kraus, E. B., Turner, J. S. A one-dimensional model of the seasonal thermocline II. The general theory and its consequences. Tellus 19, 98-106 (1967). 
49 Canuto, V. M., Howard, A., Cheng, Y., Dubovikov, M. S. Ocean turbulence. Part I: Onepoint closure model - momentum and heat vertical diffusivities. J. Phys. Oceanogr. 31, 1413-1426 (2001).

50 Canuto, V. M., Howard, A., Cheng, Y., Dubovikov, M. S. Ocean turbulence. Part II: Vertical diffusivities of momentum, heat, salt, mass and passive scalars. J. Phys. Oceanogr. 32, 240-264 (2002).

51 Thompson, L., Kelly, K. A., Darr, D., Hallberg, R. Buoyancy and mixed layer effects on the sea surface height response in an isopycnal model of the North Pacific. J. Phys. Oceanogr. 32, 3657-3670 (2003).

52 Hallberg, R. In Near-Boundary Processes and Their Parameterization: Proc. 'Aha Huliko'a Hawaiian Winter Workshop. (Honolulu, HI, University of Hawaii at Manoa, 2003), pp. 187-203.

53 Mellor, G. L., Yamada, T. Development of a turbulence closure model for geophysical fluid problems. Rev. Geophys. 20, 851-875 (1982).

54 Noh, Y., Kim, H. J. Simulations of temperature and turbulence structure of the oceanic boundary layer with the improved near-surface process. J. Geophys. Res. 104, $15621-15634$ (1999).

55 Noh, Y., Kang, Y. J., Matsuura, T., Iizuka, S. Effect of the Prandtl number in the parameterization of vertical mixing in an OGCM of the tropical Pacific. Geophys. Res. Lett. 32, L23609 (2005).

56 Pacanowski, R. C., Philander, S. G. H. Parameterization of vertical mixing in numerical models of tropical oceans. J. Phys. Oceanogr. 11, 1443-1451 (1981). 
57 Oberhuber, J. M. Simulation of the Atlantic circulation with a coupled sea ice-mixed layer-isopycnal general circulation model. Part I: Model description. J. Phys. Oceanogr. 23, 808-829 (1993).

58 Fetterer, F., Knowles, K., Meier, W., Savoie, M. Sea Ice Index. February 1979-2005. Boulder, Colorado USA: National Snow and Ice Data Center. (2002, updated 2009). 